BIANNKA POMPEO CARDOSO

Efeito do probiótico Lactobacillus acidophilus LA5 em modelo de periodontite induzida em camundongos diabéticos

São Paulo

2019 



\section{BIANNKA POMPEO CARDOSO}

Efeito do probiótico Lactobacillus acidophilus LA5 em modelo de periodontite induzida em camundongos diabéticos

\section{Versão Corrigida}

Dissertação apresentada à Faculdade de Odontologia da Universidade de São Paulo, pelo programa de Pós-Graduação em Odontologia (Periodontia), para obter o título de Mestre em Ciências Odontológicas.

Área de concentração: Periodontia

Orientador: Profa ${ }^{\mathrm{a}}$. Dr $\stackrel{\mathrm{a}}{ }$. Marcia Pinto Alves Mayer

São Paulo

2019 
Autorizo a reprodução e divulgação total ou parcial deste trabalho, por qualquer meio convencional ou eletrônico, para fins de estudo e pesquisa, desde que citada a fonte.

Catalogação-na-Publicação

Serviço de Documentação Odontológica

Faculdade de Odontologia da Universidade de São Paulo

Cardoso, Biannka Pompeo.

Efeito do probiótico Lactobacillus acidophilus LA5 em modelo de periodontite induzida em camundongos diabéticos / Biannka Pompeo Cardoso; orientador Marcia Pinto Alves Mayer -- São Paulo, 2019.

81 p. : fig. ; $30 \mathrm{~cm}$.

Dissertação (Mestrado) - Programa de Pós-Graduação em Odontologia. Área de Concentração: Periodontia - Faculdade de Odontologia da Universidade de São Paulo.

Versão corrigida

1. Periodontite. 2. Diabetes Mellitus. 3. Doenças periodontais. 4. Probióticos I. Mayer, Marcia Pinto Alves. II. Título. 
Cardoso BP. Efeito do probiótico Lactobacillus acidophilus LA5 em modelo de periodontite induzida em camundongos diabéticos. Dissertação apresentada à Faculdade de Odontologia da Universidade de São Paulo para obtenção do título de Mestre em Ciências.

Aprovado em: 15 /Abril / 2020

\section{Banca Examinadora}

Prof(a). Dr(a) Luciana Saraiva

Instituição: FOUSP Julgamento: APROVADA

Prof(a). Dr(a) Luiz Antônio Pugliesi Alves de Lima

Instituição: FOUSP Julgamento: APROVADA

Prof(a). Dr(a) Maria Regina Lorenzetti Simionato

Instituição: FOUSP Julgamento: APROVADA 



\section{AGRADECIMENTOS}

Agradeço primeiramente a Deus por ter me concedido a honra de realizar este trabalho e de tÊ-lo comigo em todos os momentos, sendo a minha fortaleza.

Agradeço ao meu esposo Augusto Cesar Santos Sllva, meu melhor amigo, meu parceiro, meu presente de Deus, que me deu forças, incentivo, motivação e que acima de tudo orou por mim todos os dias para que eu pudesse chegar ao final com êxito e alegria.

Agradeço aos meus pais e ao meu irmão, pela base e pela estrutura familiar que sempre me deram, pelo amparo, pelo amor incondicional e também por suas orações me fazendo sempre acreditar que os sonhos se realizam e que as promessas de Deus se cumprem na vida daqueles que $\mathrm{O}$ amam.

Agradeço aos meus sogros, pelas orações, pelas palavras amigas e por me fazerem sempre lembrar que somos servos de Deus e Ele nunca nos desampara.

Agradeço a Universidade de São Paulo, ao Instituto de Ciências Biomédicas e ao departamento de Microbiologia, sempre com admiração e respeito.

Agradeço a minha orientadora Profa. Dra. Marcia Pinto Alves Mayer, pelo empenho e dedicação em me orientar, pela paciência e pelo amparo em todas as fases do projeto e também da vida nesses anos compartilhados, pelo auxílio, pela amizade e por ter acreditado em mim. Um exemplo de professora, de ser humano, de excelência em tudo que se propõe a fazer. Foi uma honra ser sua orientada.

Agradeço a Dra. Pamela Pontes Amado, pela grande amizade que construímos e por ter sido meu primeiro exemplo dentro do laboratório, me inspirando e me ensinando com amor a dar os meus primeiros passos dentro do laboratório. Meu amor, meu respeito e minha admiração. 
Agradeço a todos os professores e colegas do departamento de Microbiologia.

O presente trabalho foi realizado com apoio da Coordenação de Aperfeiçoamento de Pessoal de Nível Superior - Brasil (CAPES) - Código de Financiamento 001. 


\section{RESUMO}

Cardoso BP. Efeito do probiótico Lactobacillus acidophilus LA5 em modelo de periodontite induzida em camundongos diabéticos [dissertação]. São Paulo: Universidade de São Paulo, Faculdade de Odontologia; 2019. Versão Corrigida.

O emprego dos probióticos na área da saúde é muito difundido, mas os mecanismos envolvidos no controle de doenças inflamatórias, como a periodontite e a diabetes, ainda são pouco explorados. O presente estudo visou avaliar o efeito da cepa probiótica Lactobacillus acidophilus LA5 em modelo experimental de periodontite e diabetes. 35 camundongos $\mathrm{C} 57 / \mathrm{Bl} 6$ foram submetidos à periodontite experimental pela inoculação oral de um consórcio microbiano $(P$. gingivalis W83, capsulada/afimbriada e ATCC 33277, não capsulada/fimbriada, Prevotella intermedia 17, Fusobacterium nucleatum ATCC 25586 e Streptococcus gordonii DL1). Os animais receberam inoculação via oral com 1X1011 UFC de cada cepa bacteriana 5 dias por semana por 5 semanas. A diabetes foi induzida pela ingestão de dieta hiperlipídica. $O$ probiótico $L$. acidophilus $L A 5$ foi administrado via oral em doses diárias de 1 X1095FC por todo o período experimental. Os animais foram monitorados semanalmente quanto aos níveis de glicemia sérica e ganho de peso. Após 45 dias foi determinada a tolerância a glicose. Após 47 dias, os animais foram eutanasiados, e analisadas a perda óssea alveolar por microCT, os níveis séricos de LPS e a expressão de genes associados a permeabilidade intestinal, em amostras de cólon por RTqPCR. Pudemos observar que a dieta hiperlipídica $(\mathrm{DH})$ induziu a maior nível sérico de glicose (D+SHAM) quando comparados aos animais que receberam dieta convencional (DC). A periodontite experimental com dieta hiperlipídica (D+PP) levou a maior tolerância à glicose do que apenas a dieta hiperlipídica (D+SHAM) e maiores níveis séricos de glicose em jejum. Por outro lado, a administração oral de L.acidophilus LA5 induziu a menores valores de glicemia sérica nos animais dos grupos D+PB (dieta hiperlipídica + administração de probiótico) e D+PPPB (periodontite experimental associada a dieta hiperlipídica e administração de probiótico) quando estes foram comparados aos grupos D+SHAM e D+PP, respectivamente. A administração de L.acidophilus $L A 5$, tanto no grupo que recebeu apenas a dieta hiperlipidica (D+PB) como no grupo com periodontite induzida e dieta 
hiperlipidica (D+PPPB) resultou em menor tolerância à glicose do que os respectivos controles. A análise de microtomografia do osso alveolar da maxila demonstrou que 0 consórcio microbiano foi capaz de induzir a perda do volume de osso alveolar (D+PP), sendo que os demais grupos não diferiram do controle D+SHAM, indicando que $L$. acidophilus LA5 foi capaz de controlar a perda óssea alveolar. A dieta hiperlipídica e/ou a inoculação do consórcio microbiano não foram capazes de alterar os níveis séricos de LPS. A administração de $L$. acidophilus LA5 também não alterou os níveis séricos de LPS. Porém, a administração diária de L. acidophilus LA5 alterou 0 perfil transcricional no intestino delgado na diabetes, resultando em alívio na regulação negativa de itf induzida pela dieta hiperlipídica. A expressão de itf foi regulada positivamente quando D+PPPB foi comparado ao controle D+PP (ANOVA, $p<0.05)$., L.acidophilus LA5 induziu a regulação positiva da transcrição de ocln, tanto na presença como na ausência de periodontite, embora não tenha sido observada diferença significante na expressão deste gene entre os grupos D+PP e D+PPPB. A periodontite e/ou a diabetes não interferiram na expressão relativa de muc1, no entanto, a administração do probiótico levou a regulação positiva de muc1 (não significante) quando comparados os grupos D+SHAM e D+PB, e esta regulação positiva pelo probiótico foi estatisticamente significante entre os grupos D+SHAM e D+PP e D+PPPB. Apesar das limitações dos modelos animais, o presente estudo sugere que $L$. acidophilus $L A 5$ apresenta potencial para ser utilizado como adjuvante ao tratamento da diabetes tipo 2 e da periodontite. No entanto, outros estudos experimentais elucidando seu mecanismo de ação devem ser realizados antes de seu uso clínico.

Palavras chaves: Periodontite. Diabetes. Lactobacillus acidophilus. Probiótico. 


\begin{abstract}
Cardoso BP. Effect of the probiotic Lactobacillus acidophilus LA5 in an induced periodontitis model in diabetic mice [dissertation] São Paulo: Universidade de São Paulo, Faculdade de Odontologia; 2019. Versão Corrigida.
\end{abstract}

The use of probiotics in healthcare is widely known, but their mechanisms involved in the control of inflammatory diseases, such as periodontitis and diabetes, are still poorly explored. The effect of the probiotic strain Lactobacillus acidophilus LA5 in an experimental model of periodontitis and diabetes was evaluated through determination of alveolar bone loss, serum glucose levels and glucose tolerance, weight gain, and gene expression of intestinal permeability associated genes. C57 / Bl6 mice underwent experimental periodontitis by oral inoculation of a microbial consortium $[P$. gingivalis W83(encapsulated / afimbriated) and ATCC 33277(non capsulated / fimbriated), Prevotella intermedia 17, Fusobacterium nucleatum ATCC 25586 and Streptococcus gordonii DL1]. The animals were orally inoculated with $1 \times 10^{11} \mathrm{CFU}$ of each bacterial strain 5 days a week for 5 weeks. Diabetes was induced by the intake of hyperlipidic diet. The animals were monitored weekly for blood glucose levels and weight gain. After 45 days, glucose tolerance was determined. After 47 days, the animals were euthanized and alveolar bone loss was analyzed by microCT, serum LPS levels and gene expression associated with intestinal permeability in small intestine samples by RTqPCR. It was observed that the high fat diet (DH) induced a higher serum glucose level (D + SHAM) when compared to the animals that received conventional diet (DC). Experimental periodontitis with a high fat diet $(D+P P)$ led to higher glucose tolerance than only the high fat diet (D + SHAM) and higher fasting serum glucose levels. On the other hand, oral administration of L.acidophilus LA5 induced lower serum glucose values in the animals of the $D+C P$ and $D+P P P B$ groups when compared to the $D+$ SHAM and D + PP groups, respectively. Administration of L.acidophilus LA5, both in the group receiving only the high-fat diet $(D+C P)$ and in the group with induced periodontitis and the high-fat diet (D + PPPB) resulted in lower glucose tolerance than the respective controls. Microtomography analysis of the maxillary alveolar bone showed that the microbial consortium was able to induce alveolar bone volume loss (D + PP), and the other groups did not differ from the D + SHAM control, indicating that 
L. acidophilus LA5 was able to control alveolar bone loss. Hyperlipid diet and / or microbial pool inoculation were not able to alter serum LPS levels. The administration of $L$. acidophilus $L A 5$ also did not alter serum LPS levels. However, daily administration of $\mathrm{L}$. acidophilus $\mathrm{LA5}$ altered the transcriptional profile in the small intestine in diabetes, resulting in relief in the negative regulation of itf induced by the high-fat diet. Itf expression was up-regulated when $D+P P P B$ was compared to $D+P P$ control (ANOVA, $p<0.05$ )., L. acidophilus LA5 induced up-regulation of ocln transcription, both in the presence and absence of periodontitis, although No significant difference was observed in the expression of this gene between the D + PP and D + PPPB groups. Periodontitis and / or diabetes did not interfere with relative muc1 expression; however, probiotic administration led to up-regulation of muc1 (not significant) when compared to $D+$ SHAM and $D+P B$ groups, and this up-regulation by probiotic was statistically significant between the $D+$ SHAM and D + PP and D + PPPB groups. Despite the limitations of animal models, the present study suggests that $L$. acidophilus LA5 has the potential to be used as an adjunct to the treatment of type 2 diabetes and periodontitis. However, other experimental studies elucidating its mechanism of action should be performed before its clinical use.

Keywords: Periodontitis. Diabetes. Lactobacillus acidophilus. Probiotic. 
SUMÁRIO

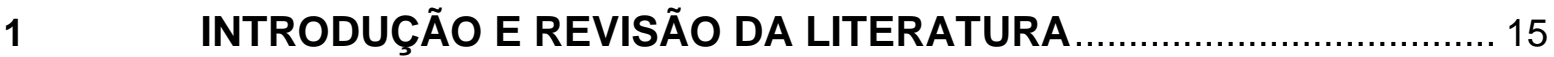

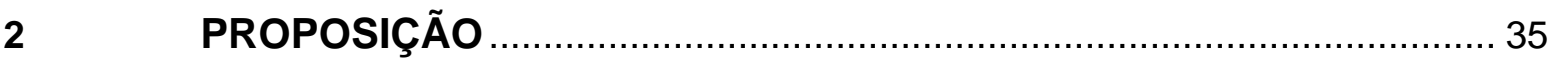

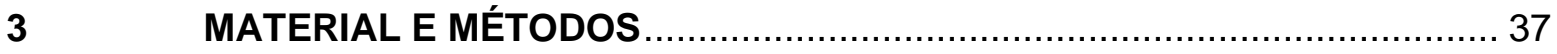

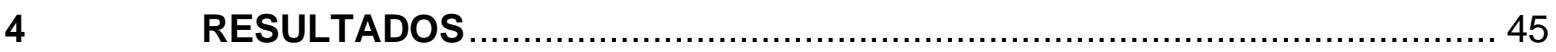

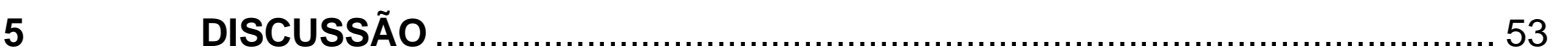

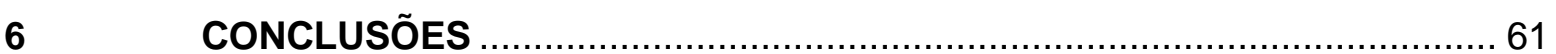

REFERÊNCIAS 





\section{INTRODUÇÃO E REVISÃO DA LITERATURA}

A periodontite é caracterizada por um processo inflamatório destrutivo que afeta os tecidos periodontais em resposta aos microrganismos presentes no biofilme supra e subgengival (Socransky et al., 1998). A periodontite crônica (PC) é a forma mais prevalente da doença, iniciada por uma comunidade microbiana disbiótica e não por periodontopatógenos selecionados (Palm et al., 2015). O tratamento das periodontites consiste em uma fase de terapia ativa, seguindo-se à terapia periodontal de suporte. Apesar da conclusão da terapia periodontal ativa, a periodontite pode progredir e a perda do elemento dental é considerada como o verdadeiro ponto final da doença (Lee et al., 2015). A periodontite foi classificada, de 1999 a novembro de 2017, como periodontite crônica (PC) e agressiva (PA), localizada ou generalizada, necrosante e como manifestação de doenças sistêmicas (Armitage, 1999), com base na extensão dos parâmetros clínicos e taxa de progressão da doença. Recentemente, foi proposta uma nova classificação, classificando a doença em periodontite necrosante (Herrera et al., 2018), periodontite como manifestação de doenças sistêmicas (Albandar; Susin; Hughes, 2018) e "periodontite", que é ainda classificada de acordo com a severidade, taxa de progressão, efeitos sistêmicos e extensão. A periodontite induzida nesse trabalho é classificada como Periodontite Estágio 2 devido a sua progressão e grau c devido a doença sistêmica estabelecida no hospedeiro (Papapanou et al., 2018; Tonetti; Greenwell; Kornman, 2018).

Estudos longitudinais em humanos demonstraram que os níveis de P.gingivalis, T. forsythia e T.denticola se relacionam com a perda periodontal na PC (Byrne et al., 2009), e estudos intervencionais demonstraram relação entre a presença destes patógenos em sítios tratados e a progressão da doença (Socransky; Haffajee, 2002). $P$. gingivalis é considerado o patógeno pedra angular na $\mathrm{PC}$, devido às suas propriedades de induzir a inflamação, mas estabelecendo um microambiente de defesas reduzidas (Hajishengallis, 2015). Estas propriedades de $P$. gingivalis, particularmente sua ação sobre o sistema complemento, aumentam a sua adaptação aos tecidos periodontais e promovem alterações ambientais que beneficiam a comunidade microbiana, favorecendo organismos inflamofílicos e perpetuando o ciclo destrutivo (Hajishengallis e Lamont, 2012). P. gingivalis pode também apresentar cápsula de polissacarídeo, implicada na evasão das defesas do hospedeiro. 
Embora a doença periodontal não se estabeleça sem a presença dos agentes microbianos, e seu controle, mecânico e por antibioticoterapia, seja a estratégia usada para o controle da destruição periodontal, o fator microbiano é apenas um dos muitos aspectos causais da complexidade etiológica da doença periodontal (Lopez et al., 2015). Apesar dos conhecimentos atuais, os fatores do hospedeiro que colaboram para o desenvolvimento de uma microbiota disbiótica subgengival, e de suscetibilidade à destruição dos tecidos periodontais, ainda são pobremente entendidos. A cavidade oral é um ecossistema onde fatores do hospedeiro, ambientais e microbianos contribuem para o estabelecimento da doença ou a manutenção da homeostase. Assim, o estilo de vida do hospedeiro, incluindo consumo de álcool e fumo (Bagaitkar et al., 2010; Dantas et al., 2012) e outros fatores como diabetes, obesidade, síndrome metabólica, osteoporose e estresse estão associados ao desenvolvimento de doenças periodontais (Genco; Borgnakke, 2013).

O diabetes mellitus (DM) é um distúrbio do metabolismo de carboidratos, proteínas e gorduras, caracterizado por hiperglicemia persistente. O diabetes tipo 1, responsável por cerca de $10 \%$ dos casos, devido à deficiência absoluta de insulina como resultado da perda maciça e progressiva de células $\beta$ secretoras de insulina, resultantes de sua destruição autoimune. A maioria dos pacientes diabéticos sofre de diabetes tipo 2 (DM2), caracterizado por falha funcional das células beta pancreáticas, que não produzem insulina suficiente para atender às crescentes demandas metabólicas impostas pela resistência periférica à insulina, que é mais comumente relacionada à obesidade; o diabetes tipo 2 é um distúrbio progressivo e, finalmente, há aumento da disfunção e morte das células $\beta$ como resultado da glico e lipotoxicidade (Furman et al., 2019). A prevalência de DM aumentou nas últimas décadas, influenciada pelo envelhecimento da população e pelo estilo de vida menos saudável, com projeções de um aumento ainda maior da carga nas próximas décadas. O DM2 tem uma forte propensão genética que se manifesta quando um paciente é exposto a um estilo de vida ocidental típico, ganha peso e se torna obeso (Kotsis et al., 2019).

A insulina, com ou sem adjuvantes, como inibidores da SGLT-2 (cotransportador-2 de sódio-glicose) ou alfa-glucosidase, continua sendo a base do tratamento para o diabetes tipo 1, enquanto, além da insulina, vários agentes estão disponíveis para o tratamento do diabetes tipo 2. Os padrões de cuidados médicos da Associação Americana de Diabetes em Diabetes focam na dieta e exercício físico 
para o tratamento do diabetes (Standards of Medical Care in Diabetes-2019) Uma revisão sistemática recente relatou que as intervenções no estilo de vida são capazes de diminuir significativamente os níveis de hemoglobina glicosilada ( $\mathrm{HbA} 1 \mathrm{c})$, principalmente quando há uma perda de peso superior a $5 \%$ do IMC inicial. No entanto, os autores ressaltam que os resultados das intervenções no controle da diabetes são muito heterogêneos (García-Molina et al., 2019) e a busca por novos agentes continua (Furman et al., 2019).

\section{Relação entre Periodontite e Diabetes}

Diabetes mellitus tipo 2 (DM2) é uma doença metabólica e multifatorial caracterizada por alterações na secreção e ação da insulina, levando a hiperglicemia. O desenvolvimento de DM2 é associado a fatores ambientais e genéticos sendo também associada a outras doenças inflamatórias como asma, hepatite crônica, bronquite crônica, gastroenterite crônica, úlceras e periodontite crônica (PC) (Lim et al., 2007; Zhang et al., 2014).

A incidência de PC é alta em pacientes diabéticos e é conhecido que a diabetes contribui para um aumento de pelo menos duas vezes na gravidade da doença periodontal, em comparação com pacientes não-diabéticos. Ambas as doenças têm uma incidência relativamente alta na população geral (diabetes 1- 6\% e periodontite 14\%). Existe uma relação causal ou modificadora direta na qual a hiperglicemia e a hiperlipidemia do diabetes resultam em alterações metabólicas que podem exacerbar a periodontite inflamatória induzida por bactérias (Soskolne; Klinger 2001).

A DM2 e a doença periodontal são consideradas respostas inadequadas ou não reguladas do sistema imunológico a estressores ambientais que atuam em um hospedeiro predisposto. Estressores ambientais mediam seus efeitos através das diferentes células envolvidas na resposta inflamatória, que incluem macrófagos/monócitos, linfócitos, fibroblastos e células endoteliais. Essas células secretam mediadores no ambiente, os quais tem seus efeitos tanto localmente quanto sistemicamente (Pickup et al,1998).

Vários estudos apontam uma associação epidemiológica entre periodontite e diabetes (Demmer et al., 2012), obesidade (Suvan et al., 2011), doenças cardiovasculares (Tonetti et al., 2013) e síndrome metabólica (Nibali et al., 2013).

Estudos prospectivos de pacientes com diabetes tipo 2 foram realizados na comunidade indiana de Pima, no rio Gila, e mostraram que a periodontite severa 
avaliada clínica ou radiograficamente no início do estudo estava significativamente associada ao mau controle metabólico $(\mathrm{HbA} 1 \mathrm{c} \geq 9 \%)$ durante um período de até 4 anos, após ajustes para idade, sexo, $\mathrm{HbA} 1 \mathrm{c}$ basal, gravidade e duração do diabetes e tabagismo (Taylor et al., 1996).

Em uma coorte baseada na comunidade de 961 indivíduos no Japão, foi demonstrado que entre aqueles com tolerância à glicose originalmente normal, bolsas periodontais profundas na linha de base estavam significativamente associadas ao desenvolvimento de intolerância à glicose no período subseqüente de 10 anos (Saito et al., 2004).

A periodontite é considerada a sexta complicação da diabetes (D'Aiuto et al., 2017), e a relação entre diabetes e periodontite é dupla, sendo que os dados sugerem que o controle da diabetes induz a melhora no quadro de periodontite, enquanto o controle da periodontite melhora o equilíbrio glicêmico em pacientes diabéticos (Pumerantz et al., 2017).

No entanto, apesar da condição periodontal ter sido ligada ao controle metabólico na diabetes, os estudos intervencionais mostraram efeitos inconsistentes. Uma revisão sistemática concluiu que, embora dois terços dos estudos sugiram que a terapia periodontal resulte em redução da $\mathrm{HbA} 1 \mathrm{c}$, ainda existem evidências insuficientes para apoiar um papel da terapia periodontal como forma de melhorar os níveis de HbA1c em pacientes diabéticos devido ao grande número de viés envolvido (Mauri-Obradors et al., 2015).

Em um estudo recente, 264 pacientes com diabetes tipo 2 e periodontite moderada a grave foram alocados aleatoriamente em um grupo de tratamento periodontal intensivo que recebeu terapia periodontal não cirúrgica e, se indicada, cirúrgica, seguida de manutenção cuidadosa ou em um grupo controle que recebeu apenas desbridamento supragengival em momentos comparáveis. Doze meses após o tratamento inicial e após os ajustes da $\mathrm{HbA} 1 \mathrm{c}$, idade, sexo, etnia, tabagismo, duração do diabetes e IMC, a redução na $\mathrm{HbA1c}$ foi de 0,6\% (IC 95\%, 0,3-0,9), maior no grupo de tratamento intensivo do que no grupo controle. (D'Aiuto et al., 2018).

\section{Modelos experimentais de diabetes tipo 2}

Ensaios em animais experimentais são úteis para avaliação do efeito de medidas para a prevenção e controle de doenças. Modelos experimentais em animais 
devem mimetizar os sinais e sintomas da doença, e devem se relacionar a etiologia comum da doença no modelo animal e no homem (Furman et al., 2019).

A obesidade está principalmente ligada ao diabetes tipo 2. A insulina é um hormônio anabólico que facilita a deposição de energia em duas formas principais glicogênio de curto prazo os carboidratos por exemplo são armazenados no nosso organismo na forma de glicogênio hepático e muscular, chamados de glicogenio de curto prazo, limitado aos músculos e ao fígado e os tri acilgliceróis (TAGs) de longo prazo também nomeado de glicogênio hepático que tem a função de manutenção da glicemia entre as refeições e o glicogênio muscular tem a função de providenciar energia para os músculos encontrados nos adipócitos do tecido adiposo. A obesidade se desenvolve como resultado da sobrecarga crônica do fluxo de ácidos graxos livres de TAG (AGL) e glicose vindos da dieta que excedem em muito a sua utilização nos tecidos. Depósitos de gordura ficam cheios; músculos e fígado acumulam glicogênio. Quando mantido, esse desequilíbrio direciona a hipertrofia dos adipócitos e a adipogênese no tecido adiposo. O primeiro sinal de resistência à insulina (RI) é o atraso na utilização da glicose no sangue em resposta à insulina, considerada intolerância à glicose e pré-diabetes. À medida que a resistência a insulina se intensifica, os níveis sanguíneos de glicose e insulina aumentam mesmo após o jejum noturno. Assim, supernutrição e sedentarismo aumentam significativamente o risco de desequilíbrio no ciclo TAG-AGL, inflamação latente e desenvolvimento de RI no tecido adiposo de indivíduos obesos. Os níveis de AGL no plasma sanguíneo são elevados na obesidade, promovendo a ativação de TLR4 nos adipócitos. Os receptores TLR4 também são expressos pelos macrófagos, células endoteliais e outras células que residem no tecido adiposo. A ativação de TLR4 em macrófagos aumenta a produção de citocinas pró-inflamatórias, como o TNFa, que ativam receptores nos adipócitos, mantendo o ciclo de inflamação latente. A diferenciação subsequente de monócitos em macrófagos pró-inflamatórios (M1) no tecido adiposo completa o ciclo vicioso, aumentando o perfil inflamatório, o que induz a IR ao suprimir a sinalização de insulina (Vorotnikov et al., 2019).

Os modelos experimentais de diabetes em animais usando aloxan ou estreptozotocina se relacionam à diabetes do tipo 1 , visto que as anormalidades observadas na doença humana são reproduzidas no modelo animal. Estes agentes levam a destruição das células $\beta$-secretoras de insulina, resultando em deficiência 
severa de insulina (Furman et al., 2019). No entanto, estes modelos diferem da diabetes tipo 1 quanto à etiologia, devido a esta ser uma doença autoimune.

Vários modelos foram propostos para mimetizar a diabetes tipo 2. O modelo animal ideal imita a transição do pré-diabetes para o DM2, quando à capacidade secretória das células $\beta$ pancreáticas não poderem mais compensar a resistência à insulina.

Os modelos para DM2 incluem animais espontaneamente diabéticos, como o camundongo db / db, o camundongo obeso da Nova Zelândia (NZO), o camundongo $\mathrm{KK}$ / Ay ou o rato diabético gordo Zucker, que exibem obesidade, resistência à insulina e, finalmente, falência de células $\beta$ e diabetes ( Asrafuzzaman et al., 2017). No entanto, o modelo ideal não deveria ser geneticamente obeso (Engel et al., 2019). Nestes modelos, um ponto importante a ser considerado é a alteração da microbiota intestinal, que acompanha as alterações inflamatórias observadas na diabetes e na obesidade (Herbert et al., 2019).

Estes modelos se relacionam muito bem com a patofisiologia da doença no homem. A HFD apresenta um percentual médio de calorias da gordura de 37,9\% (variando de 11,3 a 58\%) e deve ter uma duração mínima de oito semanas para permitir o desenvolvimento da resistência à insulina. Apesar da maioria dos estudos ter usado ratos como animal experimental, vários estudos utilizam camundongos (Engel et al., 2019; CARICILLI et al., 2014). No entanto, o modelo animal ideal ainda não foi identificado. Em particular, uma reprodução realista da doença humana não foi suficientemente alcançada; portanto, alterações humanas de longo prazo, como alterações da retina e glomerulopatias, não foram investigadas nos modelos experimentais (Engel et al., 2019).

\section{Modelos experimentais de Periodontite}

Para o desenvolvimento experimental da periodontite em modelos animais, muitos estudos utilizam o modelo de ligadura, em ratos, cachorro e primatas não humanos. Neste método um fio, geralmente de nylon ou algodão, é inserido na região do colo de dentes molares superiores. Reflete-se que as ligaduras facilitam a acumulação local de bactérias e, desse modo, aumentam a inflamação mediada por bactérias e a perda óssea (Graves et al., 2008) .No entanto, o seu uso em camundongos oferece alguns desafios, e apenas os sítios que receberam a ligadura apresentam a perda periodontal. No modelo de periodontite induzido por ligadura, a 
doença inicia-se rapidamente e a perda óssea ocorre em alguns dias em camundongos e ratos (Abe et al., 2012), diferindo do que ocorre na periodontite no homem. Além disso, no modelo de periodontite induzida por ligadura, a causa da doença está intimamente associada ao acúmulo de bactérias em regiões específicas e a resolução da doença ocorre espontaneamente após a remoção da ligadura (Abe; Hajishengallis 2013). Neste modelo, espécies bacterianas relacionadas à periodontite em humanos não foram associadas à doença (Lee et al., 2015; Oliveira et al., 2017). Por outro lado, Veillonella, Capnocytophaga, Neisseria (Oliveira et al., 2017),Rothia spp. eStreptococcusspp., usualmente associadas à saúde periodontal em humanos, foram associadas à doença induzida por ligadura em ratos. (Lee et al., 2016).

Assim, o modelo de infecção oral por bactérias isoladas da cavidade oral do homem por gavagem para indução de periodontite em camundongos é mais apropriado para abordar hipóteses relacionadas a estratégias de evasão imunológica, identificadas a partir de estudos mecanicistas da relaçãopatógeno-hospedeiro (Graves et al., 2008). Além disso, é usado com sucesso para vincular a periodontite induzida por microrganismos orais a condições sistêmicas (Lally et al., 1994), visto que no modelo de ligadura a doença periodontal ocorre em curto espaço de tempo e é localizada aos sítios de inserção da ligadura.

O modelo de infecção por gavagem oral é útil para abordar ampla variedade de hipóteses relacionadas à patogênese periodontal, que vão desde o papel da resposta do hospedeiro até fatores de virulência de periodontopatógenos e a interconexão desses fatores com parâmetros sistêmicos (Graves et al., 2008), além da avaliação do efeito de medidas preventivas e terapêuticas que buscam alterar a microbiota e modular a resposta imune.

Apesar da sua importância, $P$. gingivalis não induz doença em animais livres de germes, mas é um patógeno pedra angular, que promove mudanças na microbiota residente, que induz a periodontite (Hajishengalis; Lamond, 2012). Assim, aspectos relacionados à sua interação com outros organismos são relevantes. $P$. gingivalis é um colonizador tardio do biofilme gengival e assim apresenta capacidade de agregação a colonizadores iniciais como Streptococcus, e a outras bactérias como $P$. intermedia e $F$. nucleatum.

A infecção oral experimental por um consórcio formado por Fusobacterium nucleatum e Porphyromonas gingivalis induziu maior destruição periodontal, particularmente quando a cepa capsulada de $P$. gingivalis foi empregada (Polak et al., 
2017). A adição de $F$. nucleatum deve favorecer a colonização de $P$. gingivalis, devido à sua propriedade de agir como uma ponte entre os colonizadores iniciais e tardios do biofilme (Rickard et al., 2003). Colonizadores iniciais como S. gordonii favorecem a agregação de $P$. gingivalis ao biofilme, produzem fatores que favorecem a virulência do patógeno e a sua sobrevivência em modelos experimentais (Kuboniwa et al., 2017). Outros estudos adicionam ao consórcio microbiano para indução da doença periodontal experimental também P. intermedia (Blasco-Baque et al., 2017). Em estudo recente, a infecção oral experimental por $P$. gingivalis fimbriada associada a um isolado clínico de $P$.intermedia com alta capacidade de agregação a $P$. gingivalis (Barbosa et al., 2015) induziu maior destruição periodontal em camundongos C57BI6 do que quando um dos agentes era inoculado separadamente (Simionato, dados não publicados). Além de agregar com P. intermedia (Barbosa et al., 2015), P. intermedia colabora com o estabelecimento da disbiose oral promovida por $P$. gingivalis pois a interpaína $A$, produzida por $P$. intermedia, também degrada fatores do complemento (Potempa et al.,2009) e captura o fator $\mathrm{H}$ do complemento, um fator fisiológico inibidor do complemento (Malm et al.,2012).

\section{Microbiota Oral e Intestinal na Diabetes}

A diabetes tipo 2 é associada com fatores genéticos, hábitos como sedentarismo e dieta. A disbiose intestinal pode também ser considerada, pelo menos em parte, responsável por distúrbios metabólicos, como a diabetes (Tamboli et al., 2004). Por outro lado, a microbiota intestinal também é afetada pela obesidade, inflamação, diabetes (Arora \& Backhed, 2016), e exercício (Pasini et al., 2019). O desenvolvimento da obesidade e da resistência à insulina tem sido extensivamente estudado nas últimas décadas, mas os mecanismos subjacentes a essas alterações ainda não são completamente esclarecidos.

A microbiota intestinal contribui para várias funções fisiológicas essenciais como metabolismo energético, sinalização metabólica, formação do sistema imune e regulação da integridade da barreira do intestino (Brunkwall; Orho-Melander, 2017).

Nos estudos comparando o microbioma intestinal de diabéticos do tipo $2 \mathrm{e}$ controles, uma observação comum é a redução de bactérias produtoras de butirato no grupo com diabetes. Por outro lado, o tratamento da diabetes com metformina aumenta a abundância de bactérias produtoras de butirato e de lactobacilos (Forslundet al., 2015; Brunkwall, Orho-Melander, 2017). Além disso, os níveis de 
Akkermansia muciniphila são reduzidos em indivíduos pré-diabéticos ou recém diagnosticados com diabetes do tipo 2, e a baixa abundância deste organismo nas fezes foi sugerida como um biomarcador para a intolerância a glicose (Dao et al., 2016). A dieta rica em gordura e a diabetes estão associadas a uma maior permeabilidade intestinal, levando a endotoxemia metabólica. No fígado, o LPS promove resistência à insulina, hipertrigliceremia, acúmulo de triglicerídeos e secreção de citocinas pró-inflamatórias, promovendo a progressão da doença hepática gordurosa. No tecido adiposo, o LPS induz adipogênese, resistência à insulina, infiltração de macrófagos, estresse oxidativo e liberação de citocinas e quimiocinas pró-inflamatórias (Pascale et al., 2018).

Dietas ricas em gordura têm sido implicadas na redução da riqueza microbiana do intestino, pela presença continuada de Bacteroidetes, um aumento na abundância de Actinobacteria, junto com uma redução de Firmicutes, e várias alterações a nível de família, gênero e espécie. Os ácidos graxos saturados (SFA), monoinsaturados (MUFA), poliinsaturados (PUFA) e linolênico conjugado compartilham importantes vias de ativação / inibição do sistema imune com microrganismos intestinais, modulando perfis obesogênicos e pró-inflamatórios (Bagarolli et al., 2017).

Vários estudos relataram que bactérias periodontais específicas estão associadas ao diabetes. A glicemia modula a microbiota oral, sendo que espécies protetoras são favorecidas em diabéticos com baixos níveis de hemoglobina glicada quando comparados aos diabéticos com desequilíbrio glicêmico. Um estudo avaliou se o microbioma periodontal de pacientes com DM2 é afetado pelo status glicêmico através de biofilme subgengival de pacientes com DM2 não-fumantes com periodontite crônica e índice de massa corporal $\leq 40 \mathrm{~kg} / \mathrm{m} 2$ os pacientes foram alocados em dois grupos de acordo com o status glicêmico: sistêmico inadequado (DMI-HbA1c $\geq 8 \%$ ) e adequado (DMA-HbA1c $<7,8 \%$ ). O microbioma DMA apresentou maior diversidade que o DMl. Maiores abundâncias do grupo anginoso e Streptococcus agalactiae no DMI podem indicar que os locais subgengivais podem ser reservatórios de patógenos potencialmente invasivos. O microbioma subgengival alterado no DMl apresentou um desafio adicional no tratamento periodontal desses pacientes e na prevenção de infecções mais invasivas (Longo et al., 2015). Níveis elevados de glicose na saliva de pacientes com diabetes podem influenciar a diversidade microbiana. Níveis altos de glicose salivar (HSG; concentração de glicose $\geq 1,0 \mathrm{mg} / \mathrm{dL}$ ) foram associados a cárie dentária e gengivite e a contagem bacteriana 
de 35 (83\%) de 42 espécies foi significativamente reduzida Os autores propuseram que a hiperglicemia decorrente da obesidade e / ou da DM2 resulta em HSG e subsequente acidificação do ambiente oral, levando a uma perturbação generalizada no microbioma oral (Goodson et al., 2017).

Uma revisão sistemática abordou a natureza da microbiota oral e como ela afeta patologias sistêmicas com uma interação bidirecional. Pacientes com periodontite apresentam 27 a 53\% mais risco de desenvolver diabetes do que a população controle, sugerindo que a periodontite é um fator agravante na incidência de diabetes. Além disso, a disbiose da microbiota oral está envolvida em distúrbios periodontais e metabólicos incluindo doenças cardiovasculares, dislipidemia e diabetes. A disbiose oral na diabetes foi associada a Porphyromonas gingivalis, que é altamente prevalente em doenças periodontais e pode exacerbar a resistência à insulina (Minty et al., 2019).

\section{Mecanismos que explicam a associação entre Diabetes e Periodontite}

Apesar da correlação entre periodontite e diabetes, e dos estudos mostrando o benefício do tratamento periodontal sobre o controle glicêmico, os mecanismos moleculares envolvidos são pouco conhecidos. No contexto do controle metabólico do diabetes e / ou início do diabetes, acredita-se que a inflamação sistêmica induzida pela periodontite contribua para a resistência à insulina que, por sua vez, promove um estado disglicêmico ( Polak and Shapira, 2018).

A suscetibilidade maior à periodontite em pacientes diabéticos foi também associada à maior expressão de TLRs nos tecidos gengivais de pacientes diabéticos (Promsudthi et al., 2014), observação corroborada por estudo experimental que demonstrou maior expressão de TLR2 e TLR4 nos tecidos gengivais de ratos com diabetes induzida (Yang et al., 2014). Indivíduos com dislipidemia, periodontite crônica e diabetes tipo 2 apresentam maior expressão gênica de fatores pró-inflamatórios e anti-inflamatórios como IL-10, SOCS3, IFNA e menor expressão dos genes IFNG, IP10, IRF1, JAK1 e STAT3 na gengiva quando comparados com indivíduos saudáveis (Nepomuceno et al., 2017).

Os estudos sugerem que diabetes pode levar à alteração no metabolismo ósseo e na expressão de fatores inflamatórios, alterando o processo inflamatório decorrente da periodontite. $\mathrm{Na}$ concentração de glicose de $8,0 \mathrm{mM}$, a atividade da 
enzima fosfatase alcalina e a produção de osteocalcina diminuem significativamente. Além disso, a expressão de TNF- $\alpha$, associada à inibição da absorção de glicose intracelular, diminui em concentrações de glicose mais elevadas (12,0 e 24,0 mM )(Yamawaki et al., 2017).

\section{Permeabilidade Intestinal}

O epitélio gastrointestinal forma a maior interface do corpo com o ambiente externo. O epitélio intestinal constitui uma barreira física e bioquímica que limita seletivamente a permeação de toxinas e antígenos luminais através da mucosa, mas permite a absorção de nutrientes e água (Ahmad et al., 2017). As células epiteliais mantêm a homeostase do tecido, formando uma camada protetora para separar o meio interno do exterior. $O$ epitélio medeia o transporte direcional altamente regulado e, assim, controla a troca de água e solutos. A integridade da barreira intestinal depende da produção de muco na superfície do epitélio e também das proteínas responsáveis pela ligação entre as células, denominadas tightjunctions.

Uma alteração patológica da barreira mucosa induz a hiperativação do sistema imunológico da mucosa e inflamação crônica. No entanto, um intestino com permeabilidade aumentada devido à abertura das tightjunctions pode não ser suficiente para induzir a inflamação da mucosa, mas pode induzir uma resposta imune adaptativa devido ao aumento do desafio ao sistema imunológico (Ahmad et al., 2017)

Um dos indicadores da permeabilidade intestinal alterada é a detecção de LPS na corrente circulatória, visto que este constituinte de bactérias Gram negativas residentes no intestino pode ser translocado da luz intestinal para a corrente circulatória (Wang et al., 2010; Hajishengallis, 2015).

O muco é formado principalmente por mucinas $(m u c)$, glicoproteínas de alto peso molecular que são tipicamente expressas na superfície apical do epitélio. A expressão das mucinas é específica do epitélio intestinal e estas glicoproteínas participam de funções essenciais, como proteção, lubrificação das células epiteliais, manutenção das características epiteliais, adesão celular, diferenciação e imunidade (Josh et al.,2014). A expressão das mucinas é codificada pelos genes Muc1 e Muc2, e é alterada em muitas condições patológicas, tais como doença inflamatória intestinal e neoplasias (Niv, 2016). 
O fator trifólio intestinal (itf) é um membro da família dos peptídeos trifólio e é expresso quase exclusivamente nas células caliciformes do intestino delgado e do cólon. Sua expressão é regulada por condições inflamatórias e ulcerativas na mucosa intestinal, e a itf tem o papel de manter a integridade da mucosa e reparar a mucosa lesada. A família do fator trifólio (tff) compreende um grupo de pequenos peptídeos que são altamente expressos em tecidos contendo células produtoras de muco especialmente na mucosa que reveste o trato gastrointestinal. A itf secretada pelas células caliciformes intestinais pode estabilizar a mucosa intestinal devido à sua estrutura espacial especial. Estudos recentes revelaram que o itf pode manter a integridade da mucosa intestinal e promover a proliferação e migração celular de células epiteliais intestinais (Kjellev, 2009).

As proteínas de junção intercelular, denominadas proteínas tight junctions (TJ), constituem várias proteínas transmembranas e intracelulares, encontradas no lado apical dos complexos juncionais que conectam células epiteliais (Venugopal et al., 2019). Os estudos investigando as TJs mostraram que sua expressão é alterada em doenças inflamatórias crônicas do intestino (Ahmad et al., 2017). As tighjunction fornecem suporte estrutural às monocamadas epiteliais, regulam a permeabilidade paracelular e servem como uma barreira à difusão de proteínas através da membrana plasmática (Steed et al., 2010).

As proteínas claudina são pequenas proteínas transmembranas (20-27 kDa), com um total de 27 membros da família claudina identificados até o momento (Ahmad et al., 2017).

Claudina 1, denominada cldn1, é uma das principais proteínas estruturais na família de proteínas da tightjunction e é distribuída por toda a superfície da membrana celular na forma de uma estrutura transmembrana que atravessa a membrana quatro vezes. A cldn1 interage com as isoenzimas da creatina quinase, proteínas de junção estreita ZO1, ZO2, ZO3 e proteínas contendo o domínio PDZ, para transmitir sinais dentro e fora das células e manter a função de barreira física do epitélio intestinal (Benczik et al.,2016).

Ocludina é um componente central do complexo tighjunction que liga células epiteliais vizinhas e regula a polaridade celular, e também modula a transdução de sinal e desempenha funções durante a cicatrização de feridas epiteliais (Meredith et al., 2012). Estudos in vitro e in vivo implicam ocludina na regulação do fluxo 
macromolecular paracelular no estado estacionário e em resposta ao fator de necrose tumoral (Buschmann et al., 2013).

Como fatores comuns entre as doenças cardiovasculares, diabetes e esteatose destacam-se a inflamação sistêmica e a translocação de bactérias da microbiota intestinal (Tai et al., 2015). A microbiota oral serve como inóculo para o intestino, e é interessante notar que a inoculação oral com $P$. gingivalis em modelos experimentais leva a alteração da microbiota intestinal, sendo este um possível mecanismo para a associação entre periodontite, e doenças sistêmicas como doenças cardiovasculares e a diabetes. Apesar de não haverem evidências em humanos de que patógenos periodontais ou seus produtos poderiam aumentar a permeabilidade intestinal, evidências em modelo experimental animal demonstraram que a inoculação oral por $P$. gingivalis induz ao aumento da permeabilidade (Arimatsu et al., 2014).

Ainda em modelo experimental de periodontite em camundongos induzida pela inoculação oral com $P$. gingivalis, foi demonstrado que $P$. gingivalis não só induz alteração na permeabilidade intestinal, mas também altera o perfil transcricional dos tecidos intestinais, promovendo a regulação negativa de tip1 e ocludina proteínas da tight junction, envolvidas na permeabilidade intestinal. Além disso, a inoculação por $P$. gingivalis resultou em grande quantidade de DNA bacteriano no fígado dos animais infectados. É importante ressaltar que as mudanças na microbiota intestinal precederam as alterações inflamatórias sistêmicas (Nakajima et al., 2015).

Assim, os dados sugerem que $P$. gingivalis altera a permeabilidade do epitélio intestinal, aumentando a translocação de produtos bacterianos como LPS, o que poderia contribuir com a maior resposta inflamatória em pacientes que albergam grandes proporções deste organismo (Hajishengallis, 2015).

\section{Probióticos no controle da diabetes e da periodontite}

Devido ao papel essencial da microbiota na proteção ao hospedeiro, a recuperação do equilíbrio da microbiota pela colonização por organismos benéficos, associados aos quadros de saúde, é uma proposta atraente na prevenção da periodontite ou como adjuvante ao tratamento (Raff; Hunt, 2012). Vários estudos sugerem o efeito benéfico de probióticos como prevenção à periodontite, ou como adjuvante ao tratamento periodontal (Matsubara et al., 2016). O efeito do uso de probióticos orais poderia ser estendido também ao controle da disbiose na microbiota intestinal e sobre a diabetes. 
Probióticos são definidos, de acordo com a Organização das Nações Unidas para Agricultura e Alimentação (FAO) e com a Organização Mundial de Saúde (OMS), como microrganismos vivos, principalmente bactérias, seguros para consumo humano e que, quando ingeridos em quantidades adequadas, têm efeitos benéficos à saúde (Heczko et al., 2006). As cepas probióticas mais comuns são dos gêneros Lactobacillus e Bifidobacterium (Gupta, 2011).

Os mecanismos de ação destes organismos benéficos incluem seu efeito direto, pela produção de bacteriocinas e produtos como ácidos e peróxidos, tóxicos a vários patógenos; podem modificar o pH e o potencial de oxirredução do meio, prejudicando o estabelecimento de agentes patogênicos; inibir a adesão e formação de biofilmes e interferir na resposta do hospedeiro promovendo a inibição da produção de colagenases e citocinas pró-inflamatórias pela via do fator nuclear (NF-KB); ou modular a proliferação celular e a apoptose (Marco et al., 2006; Geier et al., 2007; Gillor et al., 2009; Gupta, 2011). 
Probióticos e intervenções nutricionais relacionadas a probióticos têm sido descritos como tendo efeitos benéficos na homeostase imunológica e na saúde intestinal. Em estudos anteriores, demonstrou-se que os mediadores solúveis de Lactobacillus rhamnosus GG (LGG) exercem efeitos benéficos em modelos préclínicos de sensibilização alérgica, infecção bacteriana e função da barreira intestinal (Zhang et al., 2014).

A suplementação com probióticos tem vários efeitos benéficos no metabolismo da glicose, um estudo clinico controlado randomizado, onde foi avaliado o efeito do probiótico Lactobacillus acidophilus La5 em gestantes com sobrepeso foram obtidos resultados no tratamento, mostrando níveis plasmáticos de glicose significativamente menores no grupo probiótico do que no iogurte convencional em jejum ( Asgharian, 2019).

A literatura mostra que amostras probióticas cultivadas in vitro com células imunes induzem a produção de IL-12, uma citocina chave na promoção da resposta Th1, caracterizada pela produção de IFN- $y$ e TNF- $\alpha$, essencial para a defesa contra infecções por patógenos intracelulares (Dalod et al., 2002). Outros probióticos induzem a produção de IL-10 (Di Giacinto et al., 2005; Niers et al., 2005). A indução de maior quantidade de IL-10 por macrófagos co-cultivados com Lactobacillus, como observado em nossos ensaios preliminares, exerceria um efeito imunorregulatório por suprimir a produção de $I L-12$ e de outras citocinas $T h 1$, o que poderia direcionar as células TCD4+ em direção à diferenciação Th2 (De Smedtet al., 1997). A redução da produção de $I L \_1 B$ é um fator relevante, pois $I L-1 \beta$ regula positivamente a expressão do fator de transcrição RORCv2, direcionando a geração de Th17 (Annunziato et al., 2008; Ivanov et al., 2006).

A suplementação de Lactobacillus rhamnosus $G G$ (LGG) reduziu significativamente a endotoxemia induzida pelo álcool, indicando redução da permeabilidade intestinal, e a esteatose hepática e melhorou a função hepática. LGG restaurou a redução induzida pelo álcool dos níveis de HIF-2a intestinal. Estudos in vitro utilizando o modelo de cultura de células Caco-2 mostraram que a adição do sobrenadante de LGG evitou a disfunção da barreira da monocamada epitelial induzida pelo álcool. Além disso, o silenciamento gênico do HIF-1 / $2 \alpha$ aboliu os efeitos do LGG, indicando que o efeito protetor do LGG é dependente do fator transcricional HIF que regula a expressão de proteínas associadas às tightjunction (Wang et al., 2010). 
O tratamento com probiótico L. casei foi capaz de destruir células $\beta$ nas ilhotas de Langerhans em diabetes tipo 1 e diminuir os níveis e aumentar o potencial de ligação da insulina em modelos experimentais de diabetes tipo 2 (Matsuzaki et al., 1997a; Matsuzaki et al., 1997b). Além disso, um produto contendo L. acidophilus NCDC14 e L. casei NCDC19 resultou em diminuição dos níveis de glicose no sangue de ratos com diabetes induzida por frutose e foi capaz de suprimir o dano oxidativo nos tecidos pancreáticos (Yadav et al., 2008). O pré-tratamento com uma mistura de probióticos formada por L. acidophilus, Bifidobacterium lactis e L. rhamnosus foi capaz de reduzir os níveis plasmáticos de glicose em ratos com diabetes induzida por aloxan (Panwar et al., 2013) enquanto ratos com diabetes tipo 2 quando tratados com $L$. reuteri GMN-32 mostraram redução nos níveis de glicose no sangue e menores alterações cardíacas causadas pelo diabetes do que observado em animais controle (Lin et al., 2014). O efeito benéfico de certos Lactobacillus sobre o equilíbrio glicêmico pode ser observado também na cavidade oral, pois diabéticos com valores de hemoglobina glicada>8,0 \% portavam menores níveis subgengivais de Lactobacillus paracasei ( $0 \%$ vs $0,12 \%)$ e de $L$. reuteri $(0,05 \%$ vs $0,27 \%)$ do que os indivíduos com valores mais baixos (Longo et al., 2018).

Um estudo recente avaliou o efeito de um probiótico comercial com mútliplas cepas de probióticos vivos(sachet "Symbiter" contendo 14 cepas probióticas dos gêneros Bifidobacterium, Lactobacillus + Lactococcus, Propionibacterium, e Acetobacter), sobre a resistência a insulina em diabéticos do tipo 2 . O uso do produto por 8 semanas em diabéticos tratados com dieta, exercício e metformina resultou em redução do índice HOMA-IR (baseado nos níveis de glicose e insulina plasmáticos em jejum) e nos níveis de hemoglobina glicada ( $\mathrm{HbA1c})(0,24 \%)$, nos níveis séricos de TNF $\alpha, I L-1 \beta$ e IL-6, em relação ao grupo placebo. É interessante notar que nem todos os pacientes do grupo probiótico tiveram o benefício, sendo que no subgrupo de pacientes que responderam ao tratamento, aredução nos níveis de $\mathrm{HbA} 1 \mathrm{c}$ foi de 0,39\%.Outras variáveis como peso, circunferência abdominal foram reduzidos no grupo de probióticos (Kobyliak et al., 2018).

O efeito no controle do perfil glicídico e lipídico da ingestão por 8 semanas do leite fermentado com probiótico (kefir) contendo Lactobacillus casei, Lactobacillus acidophilus e Bifidobacteria foi avaliado em pacientes com diabetes mellitus tipo 2, em ensaio clínico randomizado duplo-cego controlado. Houve redução nos níveis de HbA1C no grupo usando probiótico em comparação com o grupo controle, mas não 
nos níveis séricos de triglicérides, colesterol total, LDL-colesterol e HDL-colesterol, sugerindo seu efeito como adjuvante no tratamento da diabetes (Ostadrahimi et al., 2015).

A suplementação de probióticos multiespécie contendo Lactobacillus acidophilus, L. casei, L. rhamnosus, L. bulgaricus, Bifidobacterium breve, B. longum, Streptococcus thermophilus e $100 \mathrm{mg}$ de fruto-oligossacárideo (pré-biótico), em comparação com o placebo, por 8 semanas em pacientes diabéticos preveniu um aumento na glicose plasmática em jejum e resultou em uma redução dos níveis deproteínaC-reativano soro (Asemi et al., 2013).

O uso de Sachê contendo probióticos viáveis (L.acidophilus, L. casei, L. lactis e B.bifidum, Bi.longum e B. infantis) em pacientes diabéticos tipo 2 promoveram redução nos níveis de $\mathrm{HbA} 1 \mathrm{c}(0,14 \%)$, redução da insulina em jejum $(2,9 \mu \mathrm{U} / \mathrm{mL})$, e observou-se que os probióticos resistiram com sucesso à passagem pelo trato gastrointestinal (Firouzi et al., 2017).

Lactobacillus acidophilus La5 e Bifidobacterium lactis Bb12 também mostraram eficácia na redução da glicemia em jejum e na modificação de marcadores de disfunção endotelial em pacientes com síndrome metabólica (Rezazadeh et al., 2018).

Nem todos os probióticos apresentam eficiência no controle de diabetes. Por exemplo, a suplementação oral por 12 semanas com Lactobacillus reuteri DSM 17938 em pacientes com diabetes tipo 2 não afetou os níveis de $\mathrm{HbA1c}$, a esteatose hepática, a adiposidade ou a composição da microbiota intestinal. A análise mostrou que os participantes que não responderam positivamente a suplementação com $L$. reuteri apresentaram maior diversidade no microbioma intestinal no início do estudo, sugerindo que a eficácia da cepa probiótica é dependente também da composição da microbiota (Mobini et al., 2017).

Relatos sobre o papel da microbiota intestinal e do ambiente intestinal na promoção da saúde e prevenção de doenças mostraram que bactérias benéficas, como Bifidobacterium e Lactobacillus induzem a melhoria do ambiente intestinal, afetando positivamente o metabolismo, imunidade e sistema nervoso. Entre as bactérias consideradas benéficas, Akkermansia muciniphila tem destaque e sua presença foi associada ao intestino saudável e sua abundância foi inversamente correlacionada a vários estados de doença (Naito et al., 2018). Além disso, a administração de Akkermansia muciniphila reduziu o ganho de peso corporal e melhorou a tolerância à glicose em camundongos com diabetes induzida por dieta rica 
em gordura (HFD). Vesículas liberadas por A. muciniphila diminuíram a permeabilidade de monocamada de células intestinais da linhagem Caco-2 tratadas com LPS, e esta diminuição foi associada à regulação positiva da expressão da ocludina (Chelakkot et al., 2018).

Probióticos do gênero Lactobacillus mostraram resultados promissores no controle da doença periodontal em humanos. L. reuteri foi capaz de reduzir parâmetros clínicos de severidade de doença, como sangramento à sondagem e inflamação gengival (Krasse et al., 2006). O emprego de L. brevis (Riccia et al., 2007) e L. salivarius (Shimauchi et al., 2008) também promoveu a redução do índice gengival em humanos. Produtos como leite fermentado probiótico (Staab et al., 2009), chicletes contendo L. reuteri (Twetman et al., 2009) e um produto comercial à base de $L$. reuteri (Vivekananda et al., 2010) foram capazes de controlar a gengivite, reduzir citocinas pró-inflamatórias no fluido crevicular e inibir a formação de biofilme dental. Pastilhas contendo Lactobacillus rhamnosus GG (LGG) e Bifidobacterium animalis subsp. lactis BB-12 (BB-12) levaram à redução de índice de placa e índice gengival, sem alterar a composição da microbiota da saliva (Toiviainen et al., 2015). O efeito de pastilhas contendo $L$. reuterii concomitante ao tratamento com raspagem e aplanamento radicular promoveu redução nos níveis de $P$. gingivalis e $P$. intermedia na saliva e no biofilme em relação ao controle que recebeu apenas o tratamento mecânico. Além disso, o grupo com probióticos apresentou menor porcentagem de sítios com profundidade de sondagem $\geq 5 \mathrm{~mm}$ após 12 semanas de acompanhamento (Teughels et al., 2013).

O efeito de iogurte contendo L. acidophilus La5 e Bifidobacterium lactis Bb12 foi avaliado em ensaio clínico randomizado no período de quatro semanas. 0 consumo de iogurte probiótico resultou em redução dos níveis salivares de $S$. mutans (Bafna et al, 2018).

Estudos realizados neste laboratório mostraram que $L$. acidophilus $L A 5$, não foi capaz de inibir a formação de biofilme mono espécie por $P$. gingivalis mas alterou a expressão de genes de virulência como FIMA1 e Mfa1, codificando as fímbrias principal e secundária de $P$. gingivalis. Além disso, em biofilme misto, $L$. acidophilus LA5 favoreceu Streptococcus oralis e S. gordonii, colonizadores iniciais do biofilme e reduziu os níveis de $P$. gingivalis (Ishikawa et al., dados não publicados). Por outro lado, L. acidophilus LA5, entre vários lactobacilos testados, mostrou-se o mais eficiente na redução da adesão e invasão de $P$. gingivalis a células epiteliais gengivais 
e foi capaz de alterar a resposta de células epiteliais gengivais contra P.gingivalis,reduzindo drasticamente os níveis de $I L-1 \beta$ no sobrenadante (Albuquerque-Souza et al., 2019). Esta alteração no perfil de citocinas promovida pelo probiótico foi acompanhada de redução na expressão de TLR4 e NRLP3 por $L$. acidophilus LA5.

Dados prévios deste laboratório mostraram que a administração de L.acidophilus LA5 via oral diariamente em modelo experimental de periodontite induzida por consórcio microbiano resultou em controle da reabsorção do osso alveolar (Cataruci, 2019).

Para o uso clínico de probióticos, há necessidade do conhecimento das suas propriedades, com seleção do agente mais apropriado para cada quadro (Medina et al., 2007). A determinação das propriedades benéficas de uma cepa probióticas in vitro é apenas o primeiro passo para sua seleção, e os seus mecanismos devem ser determinados experimentalmente in vivo, sob diferentes estímulos.

Assim, a hipótese testada foi a de que probióticos Lactobacillus acidophilus LA5 poderiam alterar a resposta a patógenos periodontais na diabetes, e contribuir para 0 controle da periodontite e para a recuperação do equilíbrio glicêmico mesmo frente a dieta hiperlipídica.

No presente estudo, a diabetes foi induzida pela ingestão de dieta hiperlipídica e optamos por usar,na presente proposta, um modelo de periodontite experimental induzida por um consórcio bacteriano, formado por $\mathrm{P}$. gingivalis capsulada/não fimbriada e não capsulada/fimbriada, F.nucleatum, P. intermedia e S. gordonii. Este modelo permitiu o desenvolvimento da periodontite representado pela perda óssea alveolar em camundongos C57BI6 (Shimabukuro, 2019). 



\section{PROPOSIÇÃO}

\section{Objetivos gerais}

Determinar o potencial da administração oral de L. acidophilus LA5 no controle da periodontite e diabetes tipo 2 em modelo experimental animal.

\section{Objetivos específicos}

O efeito do probiótico L. acidophilus LA5 será determinado em modelo experimental in vivo de periodontite e diabetes tipo 2, avaliando-se:

- Ganho de peso, níveis séricos de glicose, e tolerância a glicose;

- Perda óssea alveolar por microCT;

- Níveis séricos de LPS;

- Expressão de genes associados à permeabilidade intestinal em amostras de cólon. 



\section{MATERIAL E MÉTODOS}

\subsection{Delineamento experimental}

Camundongos foram submetidos à periodontite experimental e diabetes tipo 2. A periodontite foi induzida por 25 inoculações por gavagem oral com microrganismos orais de origem humana, e a diabetes por ingestão de dieta hiperlipídica. O desenho experimental está apresentado na figura 3.1. O efeito do probiótico $L$. acidophilus LA5 foi determinado pela inoculação por gavagem oral da suspensão de probiótico por todo o período experimental. Os animais foram acompanhados por 47 dias, e monitorados quanto ao ganho de peso, e níveis séricos de glicose. Decorridos 45 dias da primeira inoculação, foi determinada a tolerância a glicose. No $47^{\circ}$ dia, os animais foram eutanasiados e foram realizadas as análises para determinação de perda óssea alveolar e expressão de genes associados a permeabilidade do intestino, e níveis séricos de LPS. Animais controles inoculados apenas com veículo do consórcio microbiano e/ou do probiótico foram também avaliados.

Figura 3.1 - Delineamento experimental

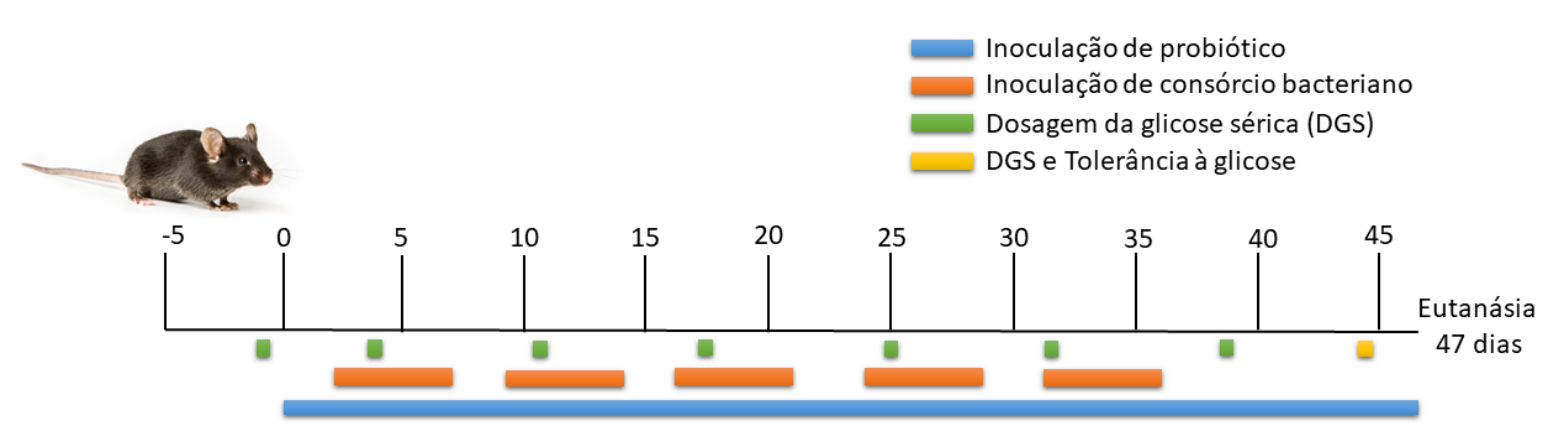




\subsection{Grupos experimentais}

Foram utilizados 35 camundongos para avaliar o desenvolvimento da diabetes foi empregado um grupo controle $(n=4)$ que recebia dieta convencional (animais normoglicêmicos) mas não foi submetido a qualquer manipulação. Os animais com indução de diabetes ( $\left.D_{+}\right)$foram distribuídos em 4 grupos experimentais $(n=8)$, na presença (PP) e ausência de periodontite (Veículo PP) (consórcio microbiano ou Veículo, respectivamente), com e sem probiótico (PB LA5 e Veículo PB, respectivamente), como descritos a seguir:

- SHAM: D+(dieta hiperlipídica), veículo PB e veículo PP;

- Controle Periodontite: D+(dieta hiperlipídica), PP, Veículo PB;

- Exp 1: D+(dieta hiperlipídica), Veículo PP, PB LA5;

- Exp2.: D+(dieta hiperlipídica), PP, PB LA5;

- Controle normoglicêmico: SHAM

\subsection{Considerações éticas}

Este projeto foi submetido à Comissão de Ética no Uso de Animais (CEUA) do ICB, tendo sido aprovado, e foi encaminhado ao CEUA da Faculdade de Odontologia da Universidade de São Paulo, em conformidade com a legislação vigente - Lei 11.794 de 8 de outubro de 2008 e Decreto 6.899 de 15 de julho de 2009 e à luz dos princípios éticos em experimentação animal elaborados pelo Colégio Brasileiro de Experimentação Animal (COBEA). (ANEXOS A e B). Número do CEUA 026/2019.

\subsection{Cepas Utilizadas e condições de cultivo}

A cepa probiótica foi cultivada em caldo e ágar MRS Lactobacilli em microaerofilia (5\% de CO2). $P$. gingivalis, $P$. intermedia, e $F$. nucleatum foram cultivados em placas de ágar sangue acrescido de $0,5 \mathrm{mg}$ hemina/mL e $1 \mathrm{mg}$ menadione $/ \mathrm{mL}$, a $37^{\circ} \mathrm{C}$, em condições anaeróbicas. Para o organismo comensal S. gordonii DL-1, alíquotas de $25 \mu \mathrm{l}$ da suspensão da bactéria estocadas a $-80^{\circ} \mathrm{C}$ foram 
inoculadas em placa de cultura de ágar infusão de cérebro e coração (BHI, BD; Becton, Dickinson and Company, Sparks, EUA) e as culturas incubadas em condição de microaerofilia a $37^{\circ} \mathrm{C}$ por $24-48$ horas. As culturas em meio líquido foram obtidas em caldo BHI suplementado com $0,5 \mathrm{mg}$ hemina/mL e $1 \mathrm{mg}$ menadione $/ \mathrm{mL}$ e incubadas em anaerobiose ( $85 \% \mathrm{~N} 2,5 \% \mathrm{H} 2$ e 10\% CO2) até atingir a densidade óptica (DO) de $\cong 1.2 \mathrm{~A}^{\circ} \mathrm{em} 600 \mathrm{~nm}$. As culturas foram centrifugadas em temperatura ambiente por $10 \mathrm{~min}$, a 3.700 rpm (2.464 Xg). Após isso, o sobrenadante foi descartado e as células precipitadas foram ressuspendidas em $500 \mu \mathrm{L}$ de leite desnatado Molico a $10 \%$ acrescido de $5 \%$ de L-glutamato de sódio monohidratado (Sigma-Aldrich), e $5 \%$ de solução de dithiothreitol (Sigma-Aldrich), a suspensões foram transferidas para criotubos (100 $\mu \mathrm{L}$ por amostra) e, imediatamente, foram congelados a $-80^{\circ} \mathrm{C}$. . As amostras foram então liofilizadas em Freezone Triad Freezer Dryers (Labconco, Flawil, Suíça) em $-40^{\circ} \mathrm{C}$, sob vácuo. O material liofilizado foi armazenado em freezer $-80^{\circ} \mathrm{C}$.

As amostras foram ressuspensas em caldo $\mathrm{BHI}$ (suplementado com $1 \mathrm{mg}$ hemina $/ \mathrm{ml}$ e $0,1 \mathrm{mg}$ menadione $/ \mathrm{ml}$ ) por 6 horas e mantidas em câmera de anaerobiose, quando então foi realizada a determinação do número de organismos viáveis /criotubo. Para o probiótico, as amostras foram ressuspensas em caldo MRS, quando então foi realizada a determinação do número de organismos viáveis /criotubo. As suspensões bacterianas foram diluídas em série em PBS $(\mathrm{pH} \mathrm{7,0)} \mathrm{e}$ alíquotas de $25 \mathrm{ul}$ foram inoculadas em triplicata na superfície de ágar sangue hemina/menadione para P. gingivalis, P. intermédia, F. nucleatum, e ágar BHI para $S$. gordonii. Após incubação em câmera de anaerobiose por 2-4 dias, as colônias foram contadas e o número de UFC /criotubo estimado. Este processo foi repetido a cada 2 meses para avaliação da manutenção da quantidade de bactérias viáveis existentes por criotubo. 


\subsection{Animais e condições de manutenção}

Os modelos experimentais de doença periodontal e/ou diabetes foram realizados em camundongos machos da linhagem C57BL6, entre 5 e 6 semanas de idade, mantidos em gaiolas com filtros micro isoladores acondicionados em estantes com ventilação e temperatura controladas no biotério do Departamento de Microbiologia, ICBUSP, recebendo água e ração à vontade. Os grupos de animais, foram mantidos separadamente, 4 camundongos por gaiola.

\subsection{Modelo experimental de periodontite}

Preparo do Inóculo: A doença periodontal experimental foi induzida por inoculação oral por gavagem de $P$. gingivalis (ATCC 33277), $P$. gingivalis (W83), P.intermedia 17, F. nucleatum ssp. Nucleatum ATCC35586 em volume de 50 4 contendo $10^{11}$ UFC de cada um dos patógenos e $10^{11}$ UFC de S. gordonii DL1. As amostras liofilizadas foram ressuspensas em $1 \mathrm{ml}$ de caldo $\mathrm{BHI}$ com hemina (10 $\mathrm{mg} / \mathrm{ml}$; Sigma-Aldrich) e menadione (1 mg/ml; Sigma-Aldrich) no dia da inoculação. Após 6 horas de incubação em condições de anaerobiose em câmara de anaerobiose $\left(85 \% \mathrm{~N}_{2}, 5 \% \mathrm{H}_{2}\right.$ e $\left.10 \% \mathrm{CO}_{2}\right)$ à $37^{\circ} \mathrm{C}$, as suspensões padronizadas foram ressuspensas em gel de carboximetilcelulose a $2 \%$ para inoculação oral por gavagem no período da tarde.

\subsection{Inoculações do consórcio microbiano}

Os animais infectados foram inoculados por gavagem oral por 25 dias, no período da tarde sendo 5 dias/semana durante as 5 primeiras semanas do ensaio. 0 esquema de inoculações pode ser visto na figura 1. Animais controles foram inoculados por gavagem oral apenas com veículo carboximetilcelulose $2 \%$ e foram também avaliados. 


\subsection{Modelo experimental de diabetes}

A diabetes foi induzida por dieta rica em lipídios $\left(5.358 \mathrm{kcal} / \mathrm{Kg}^{-1}\right)$, enquanto os controles não diabéticos receberam a dieta padrão (3.948 kcal/ $\left.\mathrm{Kg}^{-1}\right)$, ad libitum (Caricilli et al., 2011); durante todo o período experimental. A dieta hiperlipídica foi composta de 22,94 de proteína \%,32,38\% de carboidrato e 29,35\% de gordura (RHOSTER, Araçoiaba da Serra, São Paulo, Brasil).

\subsection{Tratamento com probióticos}

Foi determinada a eficácia de L. acidophilus LA5 para controlar a destruição periodontal e a diabetes. As amostras liofilizadas foram ressuspensas em $1 \mathrm{ml}$ de caldo MRS no dia da inoculação, e imediatamente ressuspensas no veículo carboximetilcelulose $2 \%$, até atingir a concentração de $1 \times 10^{10} \mathrm{UFC} / \mathrm{ml}$. O probiótico foi inoculado diariamente, por todo o período experimental, por via oral com o auxílio de uma agulha de gavagem, em alíquotas de $100 \mu \mathrm{L}$ contendo $1 \times 10^{9}$ UFC de probiótico em gel de carboximetilcelulose a $2 \%$ e PBS $(\mathrm{pH} 7,0)$. Os animais controle receberam apenas o veículo.

\subsection{Determinação dos níveis séricos de glicose}

Semanalmente, os animais foram pesados e foram determinadas as concentrações séricas de glicose após 8 horas em jejum. Uma gota de sangue foi obtida do plexo submandibular com auxílio de lanceta descartável estéril (DiagTesti®, Ipiranga, São Paulo - SP, Brasil) A determinação da concentração de glicose foi realizada usando o kit Glicose FreeStyle® Optium Neo (Abbott, São Paulo, BR), de acordo com as instruções do fabricante. 


\subsection{Tolerância a glicose}

Após 45 dias foi determinada a tolerância à glicose, de acordo com Andrikopoulos et al., 2008. Após 6 horas de jejum, foi coletado uma gota de sangue pelo plexo submandibular para a detecção do nível de glicemia no T0, após isso foi administrada dose fixa de $50 \mathrm{mg}$ de glicose $(100 \mu \mathrm{l}$ da solução de glicose a $50 \%)$ por animal, semelhante a $2 \mathrm{~g} / \mathrm{kg}$ de peso, por via intraperitoneal.

Após 15, 30, 60, e 120 minutos, foi coletada uma gota de sangue pelo plexo submandibular e as concentrações de glicose foram determinadas usando o kit Glicose FreeStyle® Optium Neo (Abbott, São Paulo, BR).

\subsection{Obtenção das amostras}

Antes da eutanásia foi realizada coleta de sangue por punção cardíaca para determinação dos níveis séricos de LPS. Após a eutanásia (47 dias), foi determinada: a destruição do osso alveolar por microCT da maxila, a expressão de genes associados a permeabilidade do intestino e os níveis de LPS no sangue.

Após remoção do tecido gengival, as hemimaxilas foram retiradas e armazenadas em formaldeído a $4 \%$ em geladeira para determinação da perda óssea alveolar. O duodeno foi obtido e uma porção de cerca de $1 \mathrm{~cm}$ mantida em RNA later em freezer a $-80^{\circ} \mathrm{C}$ até sua manipulação.

\subsection{Microtomografia computadorizada (MicroCT)}

A perda óssea alveolar foi determinada usando um microtomógrafo (SkayScan 1176 versão 1.1 , Bélgica) a $45 \mathrm{kV}$ de voltagem, 550uA de corrente, $8,71 \mu \mathrm{m}$ tamanho do pixel, filtro de aluminío $0,2 \mathrm{~mm}$. As hemimaxilas direitas dos animais foram escaneadas e as imagens analisadas calculando-se o volume ósseo (CT Analyzer software Version 1.15.4.0, SkyScan, Bruker Biospin, Kontich, Bélgica) da região 
interproximal entre o primeiro e o segundo molar (área de $50 \times 25$ pixels selecionada em 15 cortes coronais a partir da JEC do segundo molar), por examinador cego ao experimento. (LOPES et al., 2017; ROGERS et al., 2007).

\subsection{Estudo da expressão gênica (RT-PCR) da mucosa do colon intestinal A análise da expressão foi realizada como proposto por (Wang et al., 2010)}

As amostras de mucosa do cólon intestinal mantidas em RNA later foram submetidas à extração do RNA, com reagente TRIzol de acordo com o protocolo do fabricante (Invitrogen, Carlsbad, California, EUA). A quantificação de RNA de cada amostra foi realizada em NanoDrop (Thermo Fisher Scientific, Vilnius, Lituânia).

O cDNA foi sintetizado por reação de transcriptase reversa, utilizando HighCapacityc DNA Archive kit (AppliedBiosystems, Foster City, CA, EUA), seguindo o protocolo do fabricante. Foi utilizado $1,0 \mathrm{ml}$ de TRIzol por fragmento de tecido intestinal. Após a incubação por 30 minutos, foram adicionados $100 \mu \mathrm{l}$ de clorofórmio (LabSynth, São Paulo, Brasil), seguindo-se incubação por 15 minutos em temperatura ambiente e centrifugação (12.000 xg/15 minutos/4oC). O RNA na fase aquosa foi precipitado com isopropanol (LabSynth, São Paulo, Brasil) e os sais removidos com lavagem por duas vezes com etanol (75\%) (LabSynth, São Paulo, Brasil). Após a secagem em temperatura ambiente, o RNA resultante foi ressuspendido em água livre de RNAse (UltraPure ${ }^{\mathrm{TM}}$ DNase/RNase-Free Distilled Water, Invitrogen Life Technologies, Carlsbad, EUA), e tratado com desoxiribonuclease (AmbionTM DNase I, RNase-free, Invitrogen Life Technologies, Carlsbad, EUA) por 15 minutos a 25oC. A enzima foi inativada pelo calor ( $650 \mathrm{C}$ por 10 minutos) e o RNA foi quantificado por mensuração em espectrofotômetro 260 e 280 nm (Nanodrop Technologies ND-1000, Wilmington, EUA) e então utilizado para a síntese de cDNA. A quantidade e qualidade do cDNA foi estimada por espectrometria (Nanodrop ND1000 - Thermo Fisher Scientific, Vilnius, Lituânia).

A avaliação quantitativa foi realizada por PCR em tempo real. Foi avaliada a expessão dos genes que codificam as proteínas: itf, muc1 e ocludina, e actb utilizando os primers descritos na tabela 1 (Wang et al., 2010). As reações foram realizadas em termociclador Step One Plus Real-Time PCR System (Applied Biosystem, Foster City, 
Califórnia, EUA), de acordo com o protocolo a seguir: 50ng de cDNA, 0,25 $\mu \mathrm{L}$ dos iniciadores (estoque a 25pM), $5 \mu \mathrm{L}$ de Power Sybr Green® (Life Technologies Co., NY, EUA) e 3,5 $\mu \mathrm{L}$ de $\mathrm{H}_{2} \mathrm{O}$ milliQ estéril. O ciclo de amplificação foi $95^{\circ} \mathrm{C} / 15^{\prime \prime}$, $60^{\circ} \mathrm{C} / 1^{\prime}$,

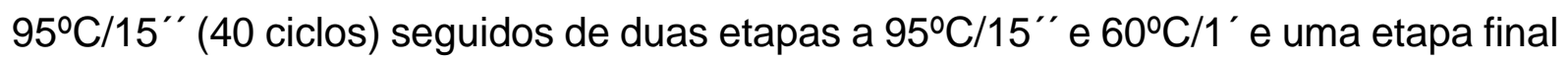
a $0,3^{\circ} \mathrm{C}-95^{\circ} \mathrm{C} / 15^{\prime \prime}$. A quantificação relativa de mRNA de cada gene alvo foi feita pelo método do $\triangle \Delta C T$ (Pfaffl, 2001), utilizando o gene da $\beta$-actina como controle endógeno, a partir de amostras duplicadas. Dados expressos em fold changes em relação ao controle D+SHAM

Tabela 3.1 - Sequência dos iniciadores utilizados nas reações de qPCR

\begin{tabular}{|c|c|c|}
\hline GENE & \multicolumn{2}{|c|}{ Sequência } \\
\hline ITF & 5'-TGGTCCTGGCCTTGCTGT-3' & 5'-GGCACACTGGTTTGCAGACA-3' \\
\hline OCLN & 5'-CCAATGTGCAGGAGTGGG-3' & 5'-CGCTGCTGTAACGAGGCT-3' \\
\hline MUC1 & 5'-GTGCCCCCTAGCAGTACCG-3' & 5'-GACGTGCCCCTACAAGTTGG-3' \\
\hline ACTB & 5'GAGACCTTCAACACCCC $3 '$ & $5^{\prime}$-ATAGCTCTTCTCCAGGGAGG-3' \\
\hline
\end{tabular}

\subsection{Determinação da integridade da barreira intestinal por análise do nível sérico de LPS}

A análise foi realizada como descrito por Wang et al., (2011).

A integridade da barreira intestinal foi avaliada por análise no soro do nível de endotoxina bacteriana. Os níveis de lipopolissacarídeo foram mensurados com a utilização do kit de amebócitos Limulus (Thermo Scientific ${ }^{\text {TM }}$, Rockford, Illinois, EUA), de acordo com as instruções do fabricante. Como controle positivo foram usadas diluições seriadas de LPS de E. coli (Sigma-Aldrich). Antes da eutanásia, após jejum de 12 horas foi realizada coleta de sangue por punção cardíaca. Obtenção do soro por centrifugação (por $15 \mathrm{~min}$, a 3.700rpm) O soro foi diluído 1:50. Comparação com escala padrão.

\subsection{Análise estatística}


Após análise da distribuição, os dados foram expressos como média \pm desvio padrão (DP). Foi utilizado o teste ANOVA de sentido único seguido do teste de Comparação Múltipla de Tukey. A significância estatística foi estabelecida em $p<0,05$. A análise foi realizada utiliando o programa GraphPad Prism® Versão 6.0c (Software GraphPad, La Jolla, CA, EUA). 


\section{RESULtAdOS}

Durante o período experimental, os animais foram monitorados quanto a quaisquer intercorrências, como alteração de pelagem e de locomoção. Não foram observadas alterações nos animais dos diferentes grupos experimentais.

Os animais foram monitorados semanalmente quanto ao ganho de peso e aos níveis séricos de glicose. Pode ser observado na figura 4.1, que os animais que receberam a dieta hiperlipídica $\left(D_{+}\right)$apresentaram maior ganho de peso durante 0 período experimental que os animais que receberam a dieta convencional. $O$ grupo DC ganhou em média 6,2g, enquanto o grupo D+ SHAM ganhou em média 13,2g, o grupo D+PP ganhou em 16,1 g, o grupo D+PB teve um ganho de peso médio de 22,7g, e o grupo D+PPPB 13,5g. Também podemos observar na Figura 5.1 o ganho de peso semanal do animais.

Figura 4.1 - Ganho de peso dos animais (em gramas) durante o período experimental de 47 dias (8 semanas dos seguintes grupos): DC (controle negativo recebendo dieta convencional), D+SHAM (dieta hiperlipídica + veículo consórcio microbiano + veículo probiótico), D+PP (dieta hiperlipídica + consórcio microbiano + veículo probiótico) e D+PPPB (dieta hiperlipídica + consórcio microbiano + probiótico L. acidophilus LA5).

$\left(^{*}\right)$ Diferença significante em relação ao grupo DC (§) Diferença significante em relação ao grupo D+SHAM $(\Delta)$ Diferença significante em relação ao grupo D+PP. Método estatístico: Kruskall Wallis $p<0,05 \%$

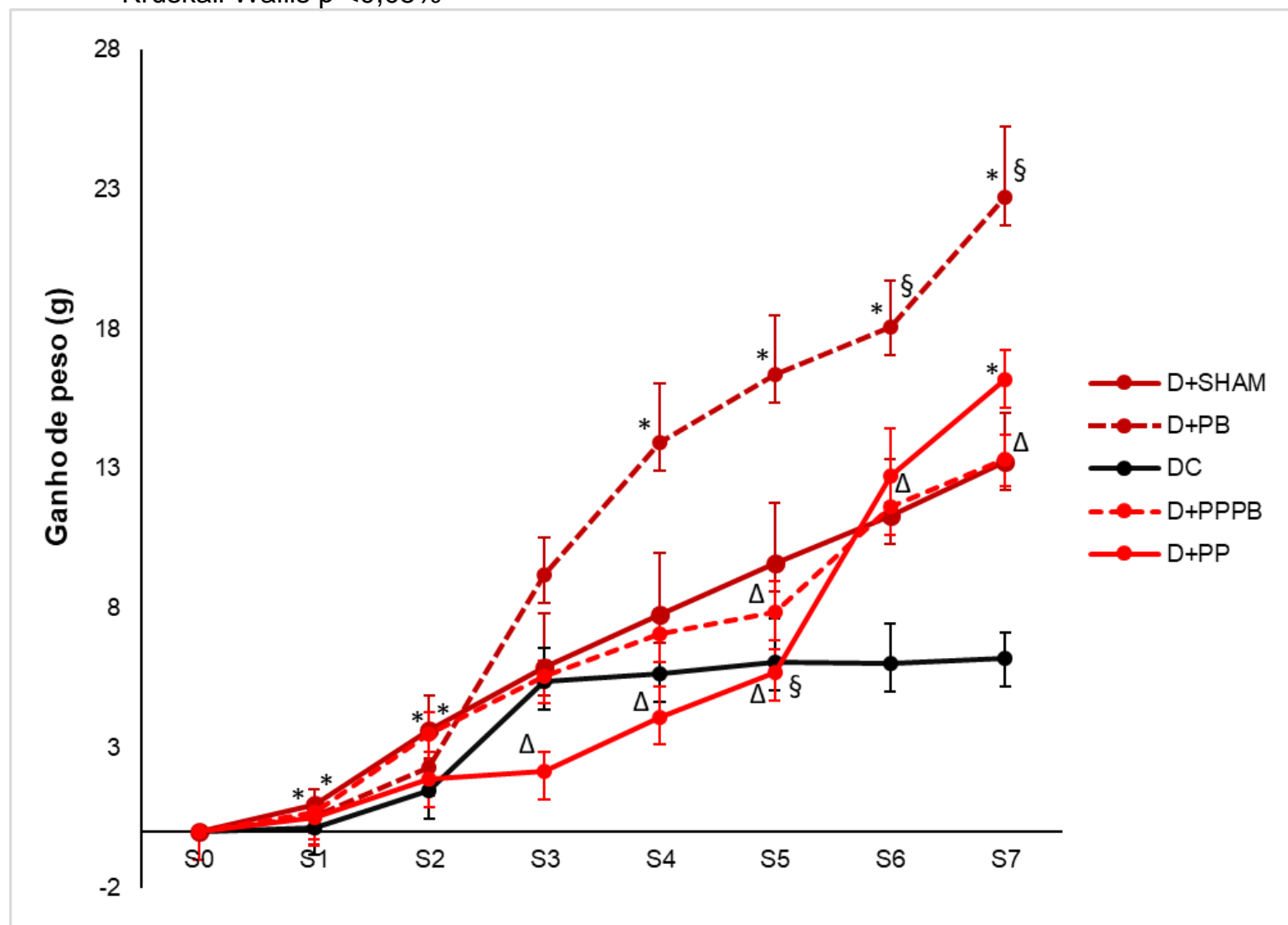

Fonte: O Autor 
A dosagem de glicose sérica durante o período experimental mostrou que a dieta hiperlipidica induziu maiores níveis séricos de glicose quando comparados aos dados obtidos de animais com dieta convencional (Figura 4.2).

A periodontite influenciou na dosagem de glicose sérica tanto no grupo D+PP, como no grupo D+PPPB. Por outro lado, pode ser observado que a administração oral de L.acidophilus LA5 induziu a menores valores de glicemia nos animais dos grupos D+PB e D+PPPB quando comparados aos grupos D+SHAM e DC respectivamente.

Figura 4.2 - Niveis séricos de glicose no período de 8 semanas com jejum de 8 horas dos seguintes grupos: DC (controle negativo recebendo dieta convencional), D+SHAM (dieta hiperlipídica + veículo consórcio microbiano + veículo probiótico), D+PP (dieta hiperlipídica + consórcio microbiano + veículo probiótico) e D+PPPB (dieta hiperlipídica + consórcio microbiano + probiótico L. acidophilus LA5). (*) Diferença significante em relação ao grupo DC, (§) Diferença significante em relação ao grupo $D+\operatorname{SHAM},(\Delta)$ Diferença significante em relação ao grupo D+PP. Método estatístico: Kruskall Wallis $p<0,05 \%$

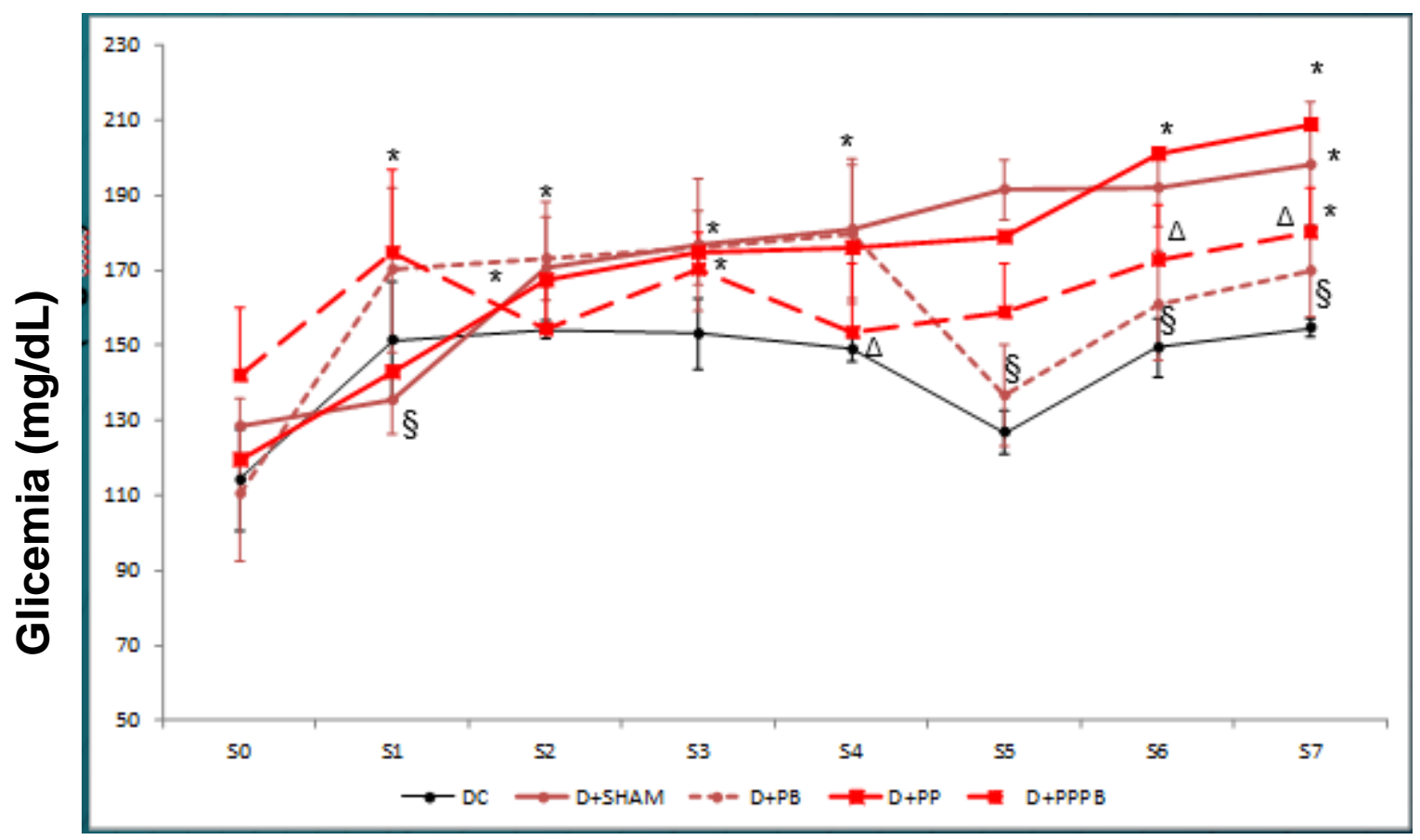

Semanas

Fonte: O Autor 
Dois dias antes da eutanásia 45 dias após o início da inoculação os animais foram submetidos a curva de tolerância a glicose, dosagem dos níveis séricos de glicose após jejum de 8 horas, seguindo-se administração de glicose intraperitoneal e dosagem da glicemia sérica em intervalos de 15 minutos, até completar 120 minutos. Os dados estão apresentados na figura 4.3.

Pode ser observado que a dieta hiperlipídica $(\mathrm{DH})$ induziu maior nível sérico de glicose em T0 (jejum), e que maiores níveis séricos de glicose foram observados em todos os períodos avaliados quando comparados os dados do grupo D+SHAM ao dados obtidos com animais recebendo a dieta convencional (DC). Além disso, em todos os intervalos avaliados, a associação de periodontite experimental com dieta hiperlipídica (D+PP) levou a menor tolerância ou maior intolerância á glicose do que apenas a dieta hiperlipídica (D+SHAM). Por outro lado, a administração de L.acidophilus LA5, tanto no grupo que recebeu apenas a dieta hiperlipidica (D+PB) como no grupo com periodontite induzida e dieta hiperlipidica (D+PPPB) resultou em maior tolerância á glicose do que os respectivos controles.

Figura 4.3 - Curva de Tolerância á glicose realizada em camundongos C57BL6 no período de 120 minutos após jejum de 6 horas dos seguintes grupos: DC (controle negativo recebendo dieta convencional), D+SHAM (dieta hiperlipídica + veículo consórcio microbiano + veículo probiótico), D+PP (dieta hiperlipídica + consórcio microbiano + veículo probiótico) e D+PPPB (dieta hiperlipídica + consórcio microbiano + probiótico L. acidophilus LA5), $\mathrm{D}+\mathrm{PB}$ (dieta hiperlipídica + probiótico). (*) Diferença significante em relação ao grupo DC, (§) Diferença significante em relação ao grupo D+SHAM, $(\Delta)$ Diferença significante em relação ao grupo D+PP. Método estatístico: Kruskall Wallis.

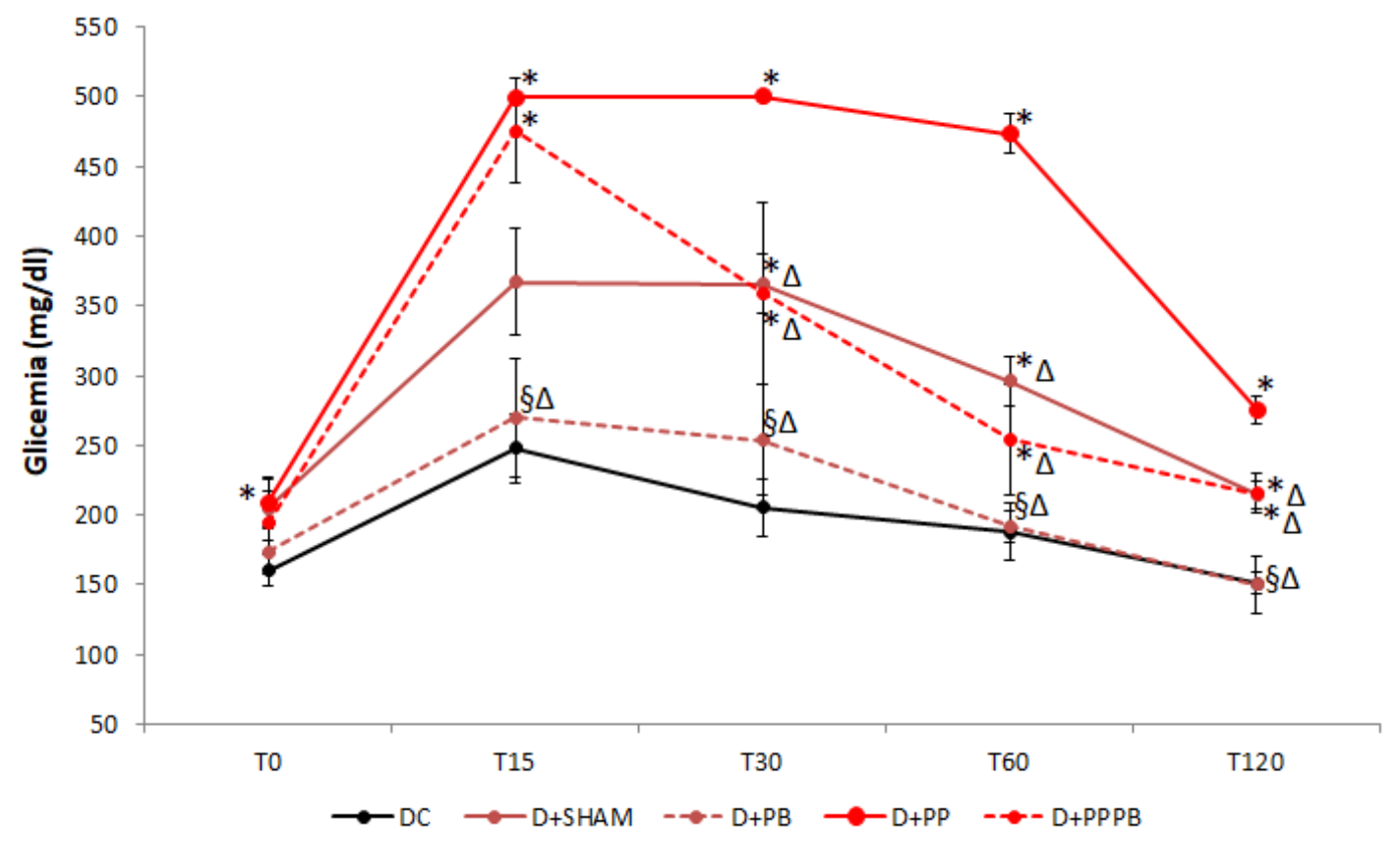

Fonte: O Autor 
Os dados obtidos pela análise do volume ósseo pelas microtomografias podem ser observados na figura 4.4 A porcentagem média de volume ósseo encontrado no grupo DC foi de aproximadamente $94 \%$ enquanto o grupo D+PP apresentou um percentual médio de 42\%, indicando que o modelo utilizado foi capaz de induzir perda periodontal. No entanto não foi observada diferença estatística no volume ósseo entre os outros grupos DC, D +SHAM, D+PPPB e D+PB, indicando que a diabetes não levou a destruição óssea siginificante; que o probiótico não induziu destruição do osso alveolar, e que a adminsitração oral do probiótico foi capaz de controlar a destruição periodontal induzida pelo consórcio microbiano nos animais diabéticos. Apesar de todos os grupos que receberam dieta hiperlipídica terem apresentado um percentual de perda do volume ósseo, apenas o grupo D+PP apresentou perda com diferença estatisticamente significante quando comparado ao controle SHAM)

Figura 4.4 - Porcentagem de volume ósseo de camundongos C57BL após o período experimental de 47 dias (8 semanas) dos seguintes grupos: DC (controle negativo recebendo dieta convencional), D+SHAM (dieta hiperlipídica + veículo consórcio microbiano + veículo probiótico), D+PP (dieta hiperlipídica + consórcio microbiano + veículo probiótico) e D+PPPB (dieta hiperlipídica + consórcio microbiano + probiótico L. acidophilus LA5), $\mathrm{D}+\mathrm{PB}$ (dieta hiperlipídica + probiótico). Método estatístico: Kruskall Wallis com pós-teste de Dunn $\left({ }^{*}\right)$ Diferença significante em relação ao grupo D+SHAM, $p<0,05$

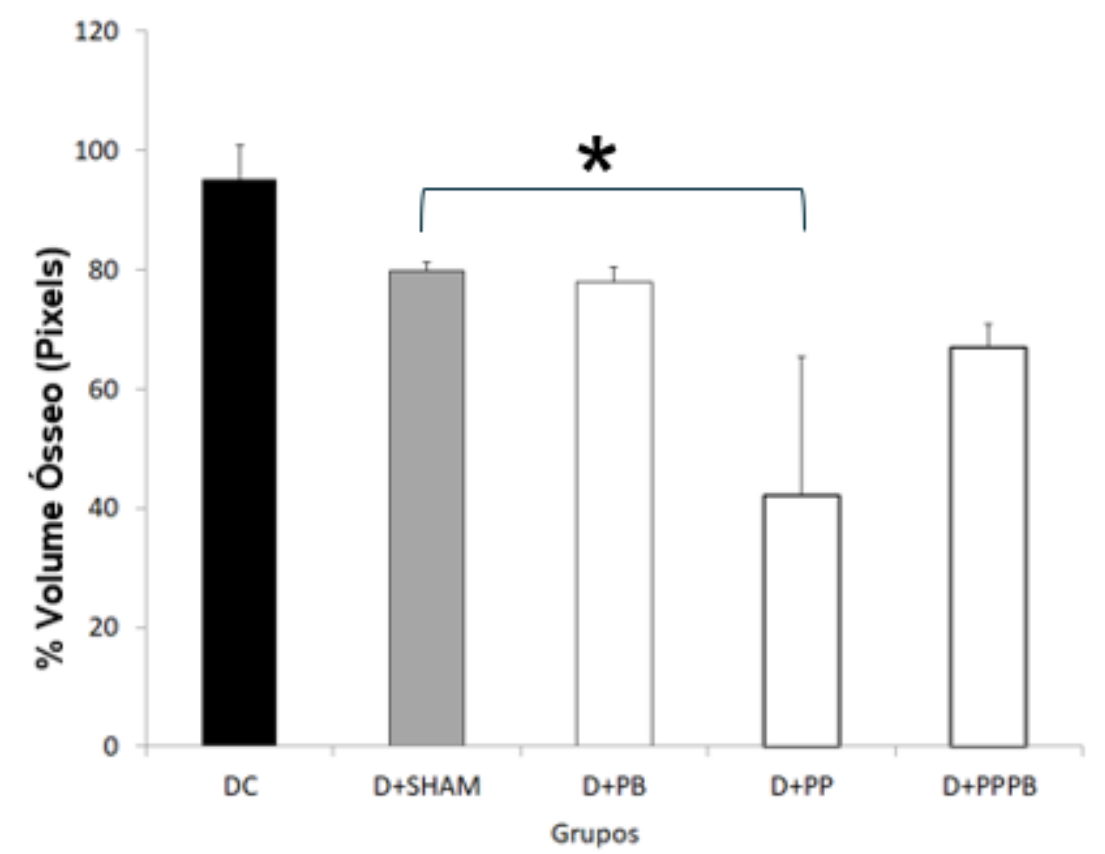

Fonte: O Autor

Para determinar se a diabetes e/ou a periodontite resultou em maiores níveis de LPS na corrente circulatória, o que poderia indicar alterações na permeabilidade do intestino, e ter repercussões sistêmicas, foram analisados os níveis séricos de LPS ao final do período experimental. 
Os dados apresentados na figura 4.5 indicam que nenhum dos tratamentos induziu a alteração nos níveis séricos de LPS.

Figura 4.5 - Níveis séricos de LPS de camundongos C57BL após o período experimental de 47 dias (8 semanas) dos seguintes grupos: D+SHAM (dieta hiperlipídica + veículo consórcio microbiano + veículo probiótico), D+PP (dieta hiperlipídica + consórcio microbiano + veículo probiótico) e D+PPPB (dieta hiperlipídica + consórcio microbiano + probiótico $L$. acidophilus LA5), D+PB(dieta hiperlipídica + probiótico). ANOVA com pós teste de Tukey $p>0,05 \%$

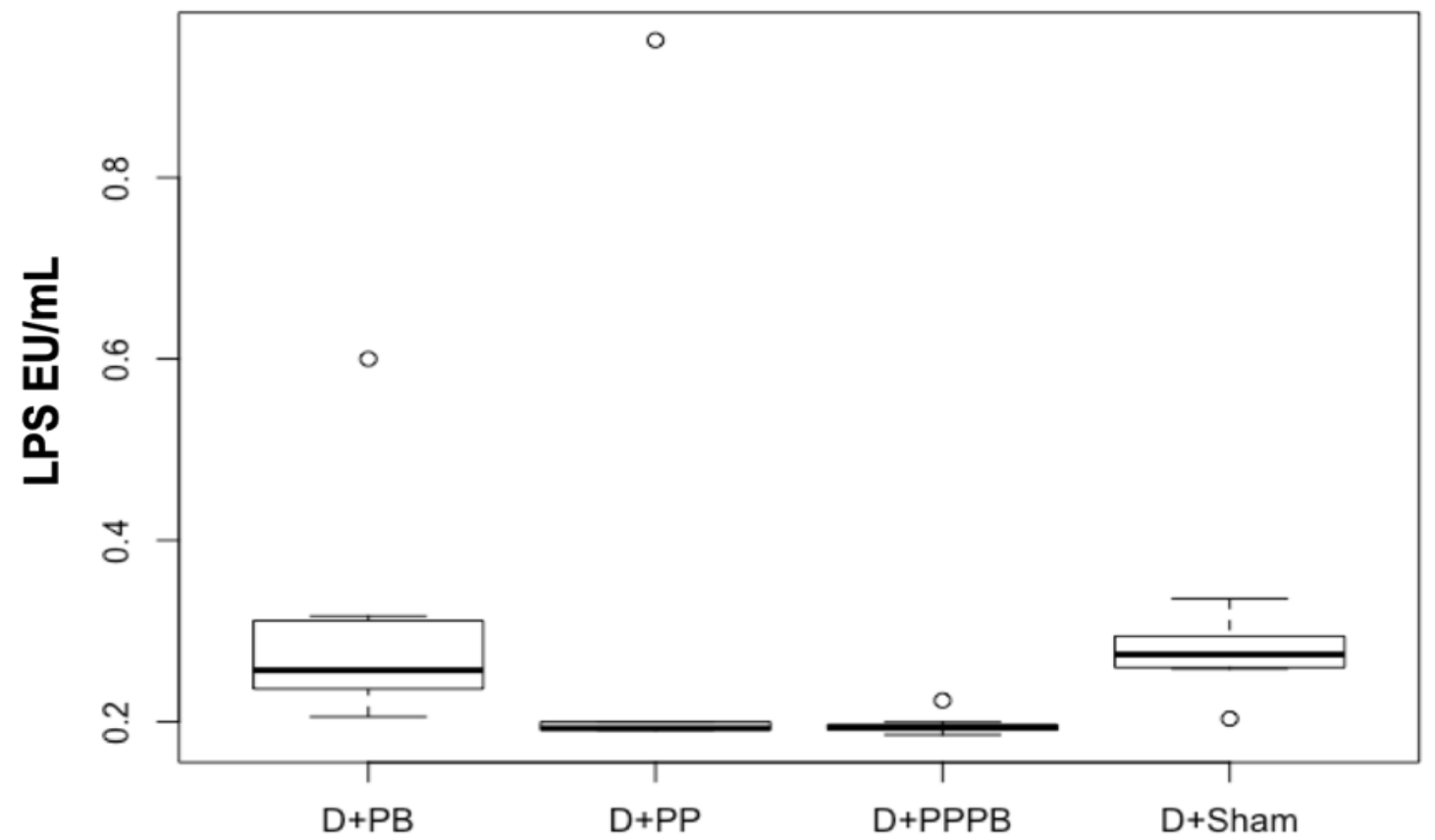

Fonte. O autor

A análise da expressão de genes associados a proteínas relacionadas à permeabilidade intestinal no intestino delgado mostrou que a dieta hiperlipidica não alterou a expressão relativa de nenhum dos genes pesquisados, quando comparados os grupos DC e D+SHAM. Por outro lado, pudemos demonstrar que a periodontite alterou a expressão de genes no intestino delgado, induzindo a regulação negativa de itf ( $\mathrm{D}+$ versus $\mathrm{D}+\mathrm{PP}$ ) (ANOVA seguido de Tukey, $\mathrm{p}<0.05$ ), mas não de muc1 ou de ocl. Por outro lado, o probiótico L.acidophilus LA5 alterou a expressão destes genes no intestino. Os resultados da expressáo relativa de cada gene (após normalização com o controle endógeno) são expressos em número de vezes em relaçao ao controle recebendo a dieta convencional, e estáo apresentados nas figuras 4.6, 4.7 e 4.8. Como apresentado na figura 6 , a expressão de itf foi regulada positivamente quando D+PPPB foi comparado ao controle D+PP, mas não houve diferença na expressão 
destes genes entre os grupos D+SHAM e D+PB (ANOVA, p>0.05). Quanto à expressão do gene ocln, que codifica a proteína de tightjunction ocludina, pudemos observar que os níveis da sua expressão foram semelhantes ao controle SHAM que recebeu a dieta convencional, quando estes foram comparados a animais diabéticos (D+SHAM) ou diabéticos com periodontite (Figura 4.7). Por outro lado, o probiótico L.acidophilus LA5 induziu a regulação positiva da transcrição de ocln, tanto na presença como na ausência de periodontite, embora não haja diferença significante na expressão deste gene entre os grupos D+PP e D+PPPB. A periodontite ou a diabetes não interferiram na expressão relativa de muc1 (Figura 4.8). No entanto, a administração do probiótico levou a regulação positiva de muc1 (não significante) quando comparados os grupos D+SHAM e D+PB, e esta regulação positiva pelo probiótico foi estatisticamente significante entre os grupos com diabetes $D_{+} \mathrm{e}$ periodontite D+PP e D+PPPB.

Figura 4.6 - Expressão relativa do gene itf por RT-qPCR em intestino delgado dos diferentes grupos: DC (controle negativo recebendo dieta convencional), D+SHAM (dieta hiperlipídica + veículo consórcio microbiano + veículo probiótico), D+PP (dieta hiperlipídica + consórcio microbiano + veículo probiótico) e D+PPPB (dieta hiperlipídica + consórcio microbiano + probiótico L. acidophilus LA5).

$\left(^{*}\right)$ Diferença estatisticamente significante na comparação do grupo (D+PPPB) em relação ao grupo (D+PP);

(ל) diferença significante na comparação do grupo (D+PP) em relação ao controle D+SHAM. ANOVA, comparação Múltipla de Tukey, $p<0.05$

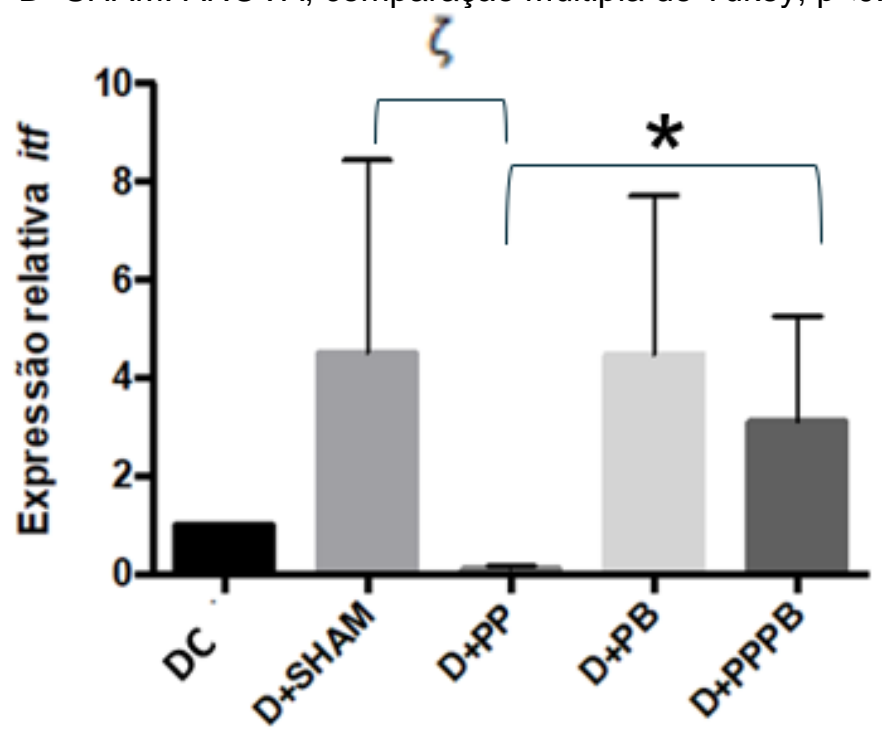

Fonte. O autor

Quanto a expressão do gene ocln, que codifica a proteína de tightjunction ocludina, pudemos observar que os níveis da sua expressão foram semelhantes ao controle (DC) que recebeu a dieta convencional, quando estes foram comparados a 
animais diabéticos (D+SHAM) ou diabéticos com periodontite (Figura 4.7). Por outro lado, o probiótico L.acidophilus LA5 induziu a regulação positiva da transcrição de ocln, tanto na presença como na ausência de periodontite, embora não haja diferença significante na expressão deste gene entre os grupos D+PP e D+PPPB.

Figura 4.7 - Expressão relativa do gene ocln por RT-qPCR em intestino delgado dos diferentes grupos: DC (controle negativo recebendo dieta convencional), D+SHAM (dieta hiperlipídica + veículo consórcio microbiano + veículo probiótico), D+PP (dieta hiperlipídica + consórcio microbiano + veículo probiótico) e D+PPPB (dieta hiperlipídica + consórcio microbiano + probiótico L. acidophilus LA5), D+PB(dieta hiperlipídica + probiótico). ANOVA, comparação Múltipla de Tukey

* Diferença significante entre D+PB ou D+PPPB e D+SHAM. $(p<0.05)$.

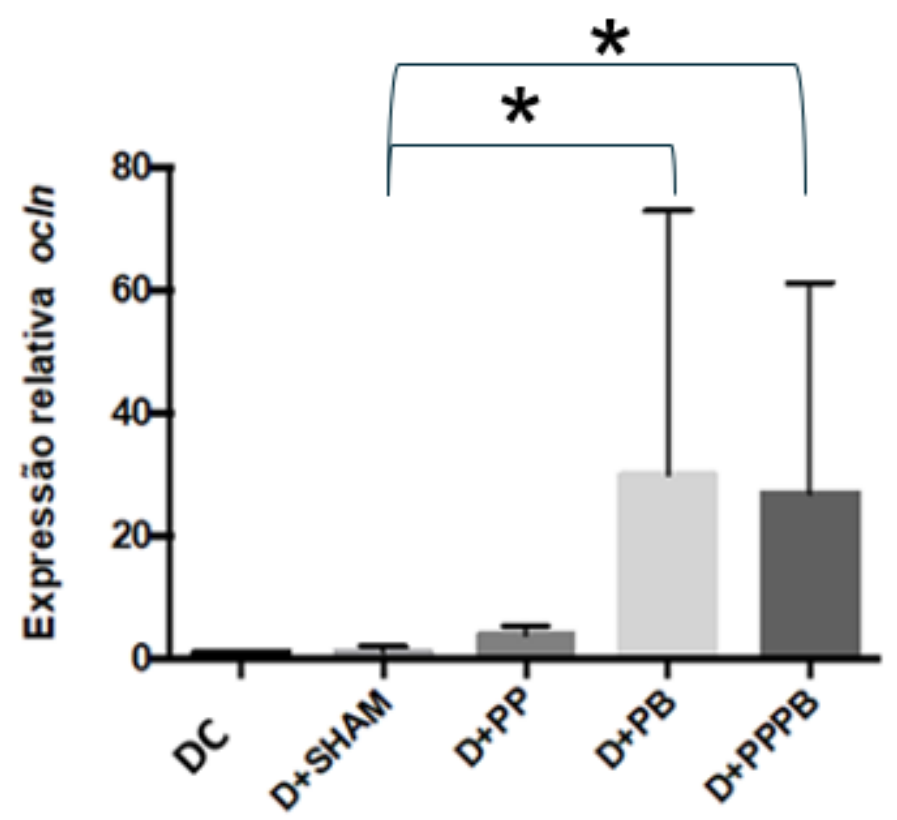

Fonte. O autor

A periodontite ou a diabetes não interferiram na expressão relativa de muc1. No entanto, a administração do probiótico levou a regulação positiva de muc1 (não significante) quando comparados os grupos D+SHAM e D+PB, e esta regulação positiva pelo probiótico foi estatisticamente significante quando comparados os grupos com diabetes e periodontite D+PP e D+PPPB. 
Figura 4.8 - Expressão relativa do gene muc1 por RT-qPCR em intestino delgado dos diferentes grupos: DC (controle negativo recebendo dieta convencional), D+SHAM (dieta hiperlipídica + veículo consórcio microbiano + veículo probiótico), D+PP (dieta hiperlipídica + consórcio microbiano + veículo probiótico) e D+PPPB (dieta hiperlipídica + consórcio microbiano + probiótico L. acidophilus LA5). ANOVA, comparação Múltipla de Tukey,

${ }^{*}$ ) diferença significante entre D+SHAM e D+PPPB,

$\left({ }^{* *}\right)$ diferença significante entre $D+P P$ e $D+P P P B, p<0,05 \%$.

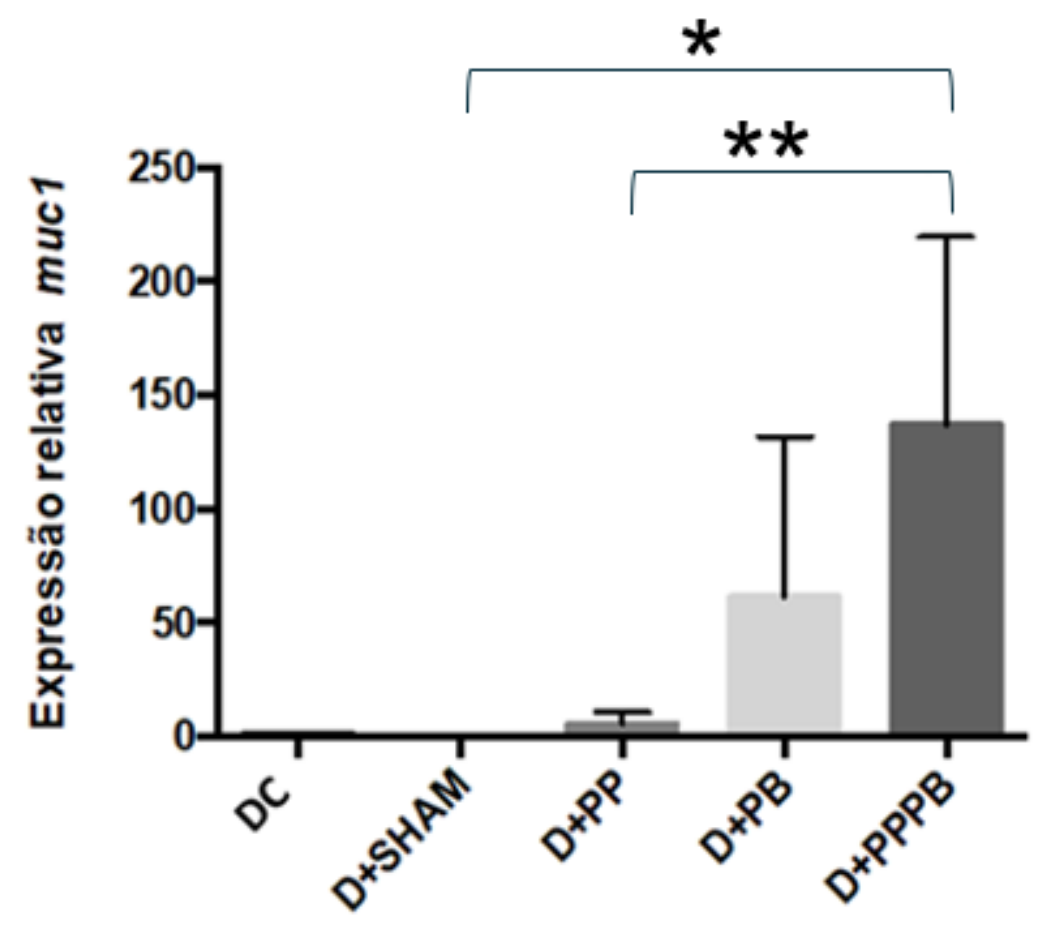

Fonte. O autor 


\section{DISCUSSÃO}

No presente estudo foi utilizado modelo animal experimental de diabetes e periodontite. A diabetes foi induzida pela ingestão de dieta hiperlipídica e optamos por usar um modelo de periodontite experimental induzida por um consórcio bacteriano, formado por $P$. gingivalis capsulada/não fimbriada e não capsulada/fimbriada, $F$. nucleatum, $P$. intermedia e $S$. gordonii. Este modelo permitiu o desenvolvimento da periodontite representado pela perda óssea alveolar em camundongos C57BI6 (Shimabukuro, 2019). Ensaios em animais experimentais são úteis para avaliação do efeito de medidas para a prevenção e controle de doenças. Modelos experimentais em animais devem mimetizar os sinais e sintomas da doença, e devem se relacionar a etiologia comum da doença no modelo animal e no homem (Furman et al., 2019). Assim, os modelos mais adequados para determinar o efeito de novos agentes para reduzir a glicose sérica em animais experimentais envolvem o uso de dieta rica em lipídios (DH). Estes modelos se relacionam muito bem com a patofisiologia da doença no homem. A dieta hiperlipídica apresenta um percentual médio de calorias da gordura de $37,9 \%$ (variando de 11,3 a 58\%) e deve ter uma duração mínima de oito semanas para permitir o desenvolvimento da resistência à insulina. Apesar da maioria dos estudos ter usado ratos como animal experimental, vários estudos utilizam camundongos (Engel et al., 2019; CARICILLI et al., 2014).

A dieta desempenha um papel decisivo na prevenção e tratamento de doenças como obesidade, diabetes, alergias e doenças inflamatórias (Fertil et al., 2017). Os dados aqui demonstrados indicam que a dieta hiperlipídica levou ao aumento dos níveis séricos de glicose e houve o desenvolvimento da tolerância a glicose. Estes dados estão de acordo com estudos prévios usando o mesmo modelo experimental de diabetes (Caricilli et al., 2014;Cândido et al., 2018).

Pacientes diabéticos não compensados geralmente apresentam complicações cardiovasculares, renais e neurais e também são mais propensos a desenvolver doenças orais graves, incluindo doença periodontal (DP) (Forbes et al., 2013). Além disso, a relação entre diabetes e periodontite é bidirecional onde os estudos sugerem que o tratamento da periodontite resulta em melhor controle glicêmico (Pumerantz et al., 2017). No presente estudo, os animais com dieta hiperlipídica que receberam o consórcio microbiano apresentaram maior nível sérico de glicose e maior tolerância a 
glicose quando comparados aos animais controle (D+SHAM). Estes dados estão de acordo com as observações de que as citocinas da DP prejudicam o controle glicêmico e contribuem para a resistência à insulina, enquanto que a hiperglicemia acelera a progressão da perda óssea alveolar (Koromantzos et al., 2011).

Assim, o modelo empregado de indução de periodontite e diabetes mostrou-se apropriado para investigar o efeito de medidas de controle, como o uso de probióticos. Pudemos determinar que a administração diária de L. acidophilus LA5 foi capaz de controlar os níveis séricos de glicose e alterar a tolerância a glicose em animais recebendo dieta hiperlipídica. Deve-se, no entanto, levar em conta a limitação de estudos de agentes antidiabetes em animais, cujos efeitos nem sempre são traduzidos para humanos, tanto em termos qualitativos da resposta, como quantitativos em termos da magnitude da resposta (Furman et al 2019). Por outro lado, mesmo uma pequena redução na glicemia ou na porcentagem de hemoglobina glicada, pode ter significado clínico no contexto da redução do desenvolvimento de complicações diabéticas a longo prazo (McGonigle et al., 2014).

Outro aspecto relevante a ser determinado para estudos em humanos referese a dose. No presente estudo, os animais pesando aproximadamente $30 \mathrm{~g}$ receberam $1 \times 10^{9}$ UFC L. acidophilus LA5/dia. Assim, a dose equivalente para um homem pesando $70 \mathrm{~kg}$ seria de $2,3 \times 10^{12} \mathrm{UFC} / \mathrm{dia}$. No entanto, a extrapolação da dose para humanos a partir de animais pode ser baseada em outros parâmetros, como a área corporal (Reagan-Shaw et al., 2007). Outras variáveis que podem interferir no efeito dos probióticos referem-se a forma de aplicação, e frequência. No presente estudo, $L$. acidophilus LA5 foi usado na cavidade oral, com 0 uso de espessante (carboximeticelulose) para aumentar o seu tempo de permanência na cavidade oral. No entanto, o efeito observado pode não ser restrito à cavidade oral, mas o probiótico pode ter atividade por interferir diretamente no intestino.

As condições ácidas são um poderoso estresse ambiental ao qual as bactérias são submetidas no trato gastrointestinal. Foi relatado que os valores de $\mathrm{pH}$ afetam fortemente a sobrevivência de bactérias, e a presença de sais biliares no ambiente é mais prejudicial para a viabilidade bacteriana do que o efeito do $\mathrm{pH} 3$ (De Angelis et al., 2004). L.acidophilus LA5 é capaz de sobreviver às condições do trato digestivo, inclusive aos sais biliares e baixo pH do estomago, sendo capaz de chegar viável ao intestino, embora estas condições promovam redução da carga microbiana. Esta cepa tem a capacidade de se adaptar as condições ambientais alterando a composição da 
superfície celular, demonstrada pela alteração na hidrofilicidade (Shakirova et al., 2013). No presente estudo, a cepa L. acidophilus LA5 foi administrada na forma liofilizada, e seu efeito pode ser demonstrado por promover alterações no intestino. No entanto, maiores estudos são necessários para rastrear esta cepa, e determinar sua sobrevivência e capacidade de colonização e de alteração do microbioma intestinal.

Um outro fator a ser ponderado sobre o efeito do probiótico sobre a diabetes e a periodontite é o momento da sua utilização. Embora probióticos tenham sido preconizados como adjuvantes da terapia periodontal e no controle da glicemia em pacientes diabéticos (Engel et al., 2019), ou seja, para serem utilizados após o estabelecimento das doenças, no presente estudo, a cepa probiótica foi utilizada para controlar o desenvolvimento das doenças mediadas pela inoculação do consórcio microbiano e pela dieta hiperlipídica, respectivamente. Assim, novos estudos são necessários para investigar o seu efeito sobre a doença já estabelecida.

O lipopolissacarídeo (LPS) do envelope externo de bactérias Gram negativas pode estimular a resposta imune inata por ativar receptors toll-like e induzir a liberação de citocinas inflamatórias (Salgaço et al., 2019). Dietas ricas em gordura estão associadas a uma redução na diversidade bacteriana intestinal, alterações na integridade da membrana, induzindo aumento da permeabilidade e aumento da translocação de LPS, alterações no sistema imunológico e geração de inflamação sistêmica de baixa intensidade. A endotoxemia instalada pode ser considerada um fator causal de inflamação subclínica relacionada a várias doenças crônicas (Caricilli et al., 2014).

Os dados de expressão genica aqui apresentados indicam que a inoculação do consórcio microbiano e a dieta hiperlipídica não foram capazes de alterar a permeabilidade intestinal a ponto de alterar os níveis de LPS séricos. Estes dados diferem de estudo que mostrou que dieta hiperlipídica ocasiona disfunções na barreira intestinal expondo o hospedeiro a altos níveis de LPS translocado que induz a produção de citocinas pró-inflamatórias (principalmente TNF- $\alpha$ e IL-6), que, por sua vez, desencadeiam inflamação subclínica e resistência à insulina (Pascale et al., 2019). Estudo prévio mostrou que a inoculação oral de $P$. gingivalis não altera os níveis séricos de endotoxina em jejum. Além disso, os níveis de endotoxina aumentaram dramaticamente quando os ratos foram alimentados, independentemente da administração de $P$. gingivalis. É interessante notar, que a 
administração de $P$. gingivalis induz maior nível sérico de LPS 1 hora após a administração, atingindo o pico às 3 horas e mantendo esses níveis mais altos até 12 horas, mas não em periodos mais prolongados (Arimatsu et al., 2014). No presente estudo, o nível sérico de LPS foi mensurado cerca de duas semanas após a última inoculação com $P$. gingivalis, e assim, o possível efeito sobre o LPS sérico não foi observado (Arimatsu et al., 2014).

Por outro lado, a administração do consórcio microbiano levou a alteração no perfil transcricional de genes associados a permeabilidade no intestino delgado. No presente estudo, foi observada redução dos níveis de expressão de itf no intestino delgado nos animais D+PP em relação ao controle D+SHAM. Estudos prévios mostraram que a exposição ao álcool causa redução significativa nos níveis de proteínas como o itf no íleo. A exposição ao álcool também reduziu as proteínas de tight junction ocludina (Wang et al., 2010), o que não foi observado nos animais onde foi induzida periodontite.

O efeito da administração oral de L.acidophilus LA5 foi observado sobre vários parâmetros. O grupo D+PB (probiótico em animais diabéticos) apresentou menores valores de glicemia sérica em jejum e menor tolerância a glicose que o grupo D+SHAM. Estudos anteriores revelaram que L.acidophilus LA5 é capaz de modular a resposta de macrófagos ativados com LPS (Ishikawa et al., dados não publicados). Além disso, estudo clínicos recente em humanos utlizando Lactobacillus acidophilus La5 e Bifidobacterium lactis Bb12 também mostrou eficácia na redução da glicemia em jejum em pacientes com síndrome metabólica (Rezazadeh et al., 2018).

Apesar deste benefício sobre a diabetes, os dados de ganho de peso revelam que $L$. acidophilus LA5 per si resultou em maior ganho de peso nos animais que recebem a dieta hiperlipídica ( $D+P B$ em relação a $D+S H A M)$. Este resultado é contraditório, pois a obesidade é um dos principatis fatores de risco para a diabetes tipo 2. Além disso, este resultado contradiz uma revisão sistemática que relatou que os efeitos benéficos de probióticos e simbióticos em estudos clínicos em pacientes com obesidade são relacionados principalmente a redução do índice de massa corporal e da massa gorda (Saez-Lara et al., 2016). Além disso, estudo avaliando modelo similar ao empregado neste estudo, mostrou que a melhoria da síndrome metabólica é acompanhada de redução do ganho de peso promovido pela dieta hiperlipídica (Zhang et al., 2019). No entanto, deve ser salientado, que neste estudo (Zhang et al., 2019), o efeito da L-arabinose sobre o peso dos animais somente foi 
observado após 16 semanas, embora outros parâmetros da síndrome metabólica tenham sido observados em menor período experimental. Assim, novos estudos com maior tempo de acompanhamento são necessários para esclarecer este resultado contraditório, onde a redução da glicemia sérica em jejum e da tolerância à glicose foi acompanhada de maior ganho de peso.

Embora os mecanismos desta cepa probiótica sobre a diabetes ainda não tenham sido elucidados, possivelmente $L$. acidophilus LA5 induz alteração na microbiota intestinal, resultando em alteração na permeabilidade intestinal e na inflamação sistemica. Os nossos dados indicam que a administração oral de L.acidophilus LA5 regula positivamente muc1, que codifica a mucina 1 , ocl que codifica a proteína de tightjunction ocludina, e itf, que codifica pequenos peptídeos produzidos com domínio trefoil, sugerindo que $L$ acidophilus $L A 5$ atinge o intestino na sua forma viável e altera o perfil transcricional no intestino delgado na diabetes, resultando em melhora em parametros clínicos.

L. acidophilus LA5 não foi capaz de induzir perda óssea alveolar, mostrando a sua segurança para uso oral, pelo menos quanto aos tecidos de suporte dos dentes. Além disso, os dados revelam que L. acidophilus LA5 foi capaz de controlar a perda óssea alveolar induzida pela administração do consórcio microbiano mesmo em animais diabéticos. Vários estudos mostraram o efeito benéfico de cepas probióticas no controle da periodontite, tanto em animais experimentais (Gatej et al., 2018), como em humanos (Matsubara et al., 2016). Estudos prévios deste laboratório já havia mostrado o benefício de B. bifidum 1622A (Shimabukuro, 2019), e de L.acidophilus LA5 e L. rhamnosus LR32 em modelo murino de periodontite (Cataruci, 2019). L.acidophilus LA5 foi selecionado para o presente estudo devido à sua atividade imunomodulatória, tanto em ensaios em linhagens celulares como in vivo. Outros estudos devem ainda ser conduzidos, analisando o microbioma oral e a expressão de genes e produção de mediadores inflamatórios no tecido gengival para explicar os mecanismos envolvidos neste efeito benéfico. O equilíbrio entre as complexas interações da comunidade microbiana intestinal é importante para a saúde intestinal e bactérias probióticas podem melhorar o equilíbrio bacteriano e têm sido usadas para tratar doenças gastrointestinais (Shiou et al., 2013). A permeabilidade intestinal é regulada por grande número de fatores, e avaliamos apenas três proteínas (ocludina, itf e muc1), assim é possível que a periodontite e a diabetes tenham afetado a expressão de outros genes não avaliados no presente estudo. 
Nossos dados sugerem que a cepa probiótica pode ter atuado de maneira indireta sobre a periodontite, pela modulação de genes associados a permeablidade intestinal. Estudos anteriores formularam a hipótese de que bactérias orais teriam efeito sobre a inflamação sistêmica por romperem o equilíbrio da microbiota intestinal, levando a ruptura da integridade da mucosa intestinal (Hajishengallis, 2015). Nossos dados apontam que a cepa probiótica foi capaz de restaurar parcialmente a transcrição de itf, que foi regulada negativamente pelo consórcio microbiano (D+PP) em animais diabéticos. Além disso, a administração de L. acidophilus LA5 regulou positivamente muc1 e ocl, nos animais dos grupos $\mathrm{D}+\mathrm{PB}$ e $\mathrm{D}+\mathrm{PPPb}$ em relação aos seus controles D+SHAM e D+PP.

Embora não tenham sido encontrados dados na literatura sobre o efeito de $L$. acidophilus LA5 na redução da permeabilidade intestinal, já foi relatada esta associação com probióticos. A cepa $B$ animalis subsp lactis 420 reduz a endotoxemia, a inflamação e a translocação de LPS em modelo animal experimental (Amar et al., 2011). A administração de Lactobacillus rhamnosus $G G$ em animais experimentais com doença hepática induzida por alcool levou a aumento nos níveis de mRNA do fator indutor de hipóxia (HIF)-2a, um fator de transcrição de ITF, além de regular positivamente muc1 e muc2, e ocl (Wang et al., 2011).

Assim os dados sugerem que $L$. acidophilus LA5 promoveu um ambiente intestinal favorável, alterando a expressão de genes associados à integridade intestinal. Este efeito possivelmente deve-se a alteração na microbiota intestinal. Após a ingestão de probióticos, observa-se geralmente melhoria nos sintomas da diabetes tipo 2 devido à melhor integridade intestinal, redução de níveis sistêmicos de LPS , e melhor sensibilidade periférica à insulina (Salgaço et al., 2019). A periodontite também se relaciona à perda da integridade intestinal (Hajishengallis, 2015), e estudos recentes do grupo do Laboratório de Microbiologia oral do ICBUSP mostrara disbiose da microbiota intestina na periodontite agressiva e periodontite crônica (Amado, tese de doutorado, 2019). Assim, os dados sugerem que efeitos benéficos da cepa probiótica $L$. acidophilus $L A 5$ no controle da periodontite e da diabetes observados no presente estudo podem estar associados a melhoria da integridade intestinal. 



\section{CONCLUSÕES}

Frente as limitações do modelo experimental empregado, podemos concluir que a administração oral de L.acidophilus LA5 apresenta potencial para o controle da periodontite e da diabetes tipo 2 .

Utilizando modelo experimental murino de diabetes e periodontite, a administração oral de L. acidophilus LA5 foi capaz de:

- controlar os níveis séricos de glicose e melhorar a tolerância a glicose em animais diabéticos, com ou sem periodontite induzida por consórcio microbiano.

- promoveu maior ganho de peso nos animais recebendo dieta hiperlipídica, mas não naqueles que receberam a dieta hiperlipidica e inoculados com o consórcio microbiano indutor de peridontite.

- foi capaz de controlar a perda óssea alveolar induzida pelo consórcio microbiano.

- não alterou os níveis séricos de LPS, que foram similares em todos os grupos experimentais.

- alterou a expressão de genes associados à permeabilidade intestinal, aliviando o efeito da diabetes sobre a regulação negativa de itf, e regulando positivamente os genes ocl e muc1.

Apesar das limitações dos modelos animais, o presente estudo sugere que $L$. acidophilus LA5 apresenta potencial para ser utilizado como adjuvante ao tratamento da diabetes tipo 2 e da periodontite. No entanto, outros estudos experimentais elucidando seu mecanismo de ação devem ser realizados antes de seu uso clínico. 





\section{REFERÊNCIAS}

Albandar JM, Susin C, Hughes FJ. Manifestations of systemic diseases and conditions that affect the periodontal attachment apparatus: Case definitions and diagnostic considerations. J Periodontol. 2018 Jun;89 Suppl 1:S183-S203. doi: 10.1002/JPER.16-0480.

Amar J, Chabo C, Waget A, Klopp P, Vachoux C, Bermúdez-Humarán LG, Smirnova $\mathrm{N}$, Bergé M, Sulpice T, Lahtinen S, Ouwehand A, Langella P, Rautonen N, Sansonetti PJ, Burcelin R. Intestinal mucosal adherence and translocation of commensal bacteria at the early onset of type 2 diabetes: molecular mechanisms and probiotic treatment. EMBO Mol Med. 2011 Sep;3(9):559-72. doi: 10.1002/emmm.201100159.

Albuquerque-Souza E, Balzarini D, Ando-Suguimoto ES, Ishikawa KH, Simionato MRL, Holzhausen M, Mayer MPA. Probiotics alter the immune response of gingival epithelial cells challenged by Porphyromonas. gingivalis. J Periodontal Res. 2019 Apr;54(2):115-127. doi: 10.1111/jre.12608

Abe T, Hosur KB, Hajishengallis E, Reis ES, Ricklin D, Lambris JD, Hajishengallis G. Local complement-targeted intervention in periodontitis: proof-of-concept using a $\mathrm{C} 5 \mathrm{a}$ receptor (CD88) antagonist. J Immunol. 2012 Dec 1;189(11):5442-8. doi: 10.4049/jimmunol.1202339.

Abe T, Hajishengallis G. Optimization of the ligature-induced periodontitis model in mice. J Immunol Methods. 2013 Aug 30;394(1-2):49-54. doi:

10.1016/j.jim.2013.05.002.

Annunziato F, Cosmi L, Liotta F, Maggi E, Romagnani S. The phenotype of human Th17 cells and their precursors, the cytokines that mediate their differentiation and the role of Th17 cells in inflammation. Int Immunol. 2008 Nov;20(11):1361-8. doi: 10.1093/intimm/dxn106.

Armitage GC. Development of a classification system for periodontal diseases and conditions. Ann Periodontol. 1999 Dec;4(1):1-6. Review.

Arora T, Bäckhed F. The gut microbiota and metabolic disease: current understanding and future perspectives. J Intern Med. 2016 Oct;280(4):339-49. doi: 10.1111/joim.12508. 
Asemi Z, Zare Z, Shakeri H, Sabihi S-S, Esmaillzadeh A. Effect of multispecies probiotic supplements on metabolic profiles, hs-CRP, and oxidative stress in patients with type 2 diabetes. Ann Nutr Metab. 2013;63(1-2):1-9. doi: 10.1159/000349922.

Asgharian H, Homayouni-Rad A, Mirghafourvand M, Mohammad-AlizadehCharandabi S. Effect of probiotic yoghurt on plasma glucose in overweight and obese pregnant women: a randomized controlled clinical trial. Eur J Nutr. 2019 May 8. doi: $10.1007 / \mathrm{s} 00394-019-01900-1$

Arimatsu K, Yamada H, Miyazawa H, Minagawa T, Nakajima M, Ryder MI, Gotoh K, Motooka D, Nakamura S, lida T, Yamazaki K. Oral pathobiont induces systemic inflammation and metabolic changes associated with alteration of gut microbiota. Sci Rep. 2014 May 6;4:4828. doi: 10.1038/srep04828.

Bafna HP, Ajithkrishnan CG, Kalantharakath T, Singh RP, Kalyan P, Vathar JB, Patel HR. Effect of Short-term Consumption of Amul Probiotic Yogurt Containing Lactobacillus acidophilus La5 and Bifidobacterium Lactis Bb12 on Salivary Streptococcus mutans Count in High Caries Risk Individuals. Int J Appl Basic Med Res. 2018 Apr-Jun;8(2):111-115. doi: 10.4103/ijabmr.IJABMR_447_16.

Bagaitkar J, Demuth DR, Daep CA, Renaud DE, Pierce DL, Scott DA. Tobacco upregulates $P$. gingivalis fimbrial proteins which induce TLR2 hyposensitivity. PLoS One. 2010 May 4;5(5):e9323. doi: 10.1371/journal.pone.0009323.

Barbosa GM, Colombo AV, Rodrigues PH, Simionato MR. Correction: Intraspecies Variability Affects Heterotypic Biofilms of Porphyromonas gingivalis and Prevotella intermedia: Evidences of Strain-Dependence Biofilm Modulation by Physical Contact and by Released Soluble Factors. PLoS One. 2015 Nov 25;10(11):e0143903. doi: 10.1371/journal.pone.0143903.

Bagarolli RA, Tobar N, Oliveira AG, Araújo TG, Carvalho BM, Rocha GZ, Vecina JF, Calisto K, Guadagnini D, Prada PO, Santos A, Saad STO, Saad MJA. Probiotics modulate gut microbiota and improve insulin sensitivity in DIO mice. J Nutr Biochem. 2017 Dec;50:16-25. doi: 10.1016/j.jnutbio.2017.08.006.

Benczik M, Galamb A, Koiss R, Kovács A, Járay B, Székely T, Szekerczés T, Schaff Z, Sobel G, Jeney C. Claudin-1 as a biomarker of cervical cytology and histology. Pathol Oncol Res. 2016;22:179-188. doi: 10.1007/s12253-015-9990- 
Blasco-Baque V, Garidou L, Pomié C, Escoula Q, Loubieres P, Le Gall-David S, Lemaitre M, Nicolas S, Klopp P, Waget A, Azalbert V, Colom A, Bonnaure-Mallet M, Kemoun P, Serino M, Burcelin R. Periodontitis induced by Porphyromonas gingivalis drives periodontal microbiota dysbiosis and insulin resistance via an impaired adaptive immune response. Gut. 2017 May;66(5):872-885. doi: 10.1136/gutjnl-2015309897.

Brunkwall L, Orho-Melander M. The gut microbiome as a target for prevention and treatment of hyperglycaemia in type 2 diabetes: From current human evidence to future possibilities. Diabetologia. 2017;60:943-951. doi: 10.1007/s00125-017-4278-3

Buschmann M. M., Shen L., Rajapakse H., Raleigh D. R., Wang Y., Wang Y., Lingaraju A., Zha J., Abbott E., Mcauley E. M., Breskin L. A., WU L., Anderson K., Turner J. R., AND Weber C. R. (2013) Occludin OCEL-domain interactions are required for maintenance and regulation of the tight junction barrier to macromolecular flux. Mol. Biol. Cell 24, 3056-3068 10.1091/mbc.e12-09-0688

Byrne SJ, Dashper SG, Darby IB, Adams GG, Hoffmann B, Reynolds EC.

Progression of chronic periodontitis can be predicted by the levels of Porphyromonas gingivalis and Treponema denticola in subgingival plaque. Oral Microbiol Immunol. 2009 Dec;24(6):469-77. doi: 10.1111/j.1399-302X.2009.00544.x.

Caricilli AM, Saad MJ. The role of gut microbiota on insulin resistance. Nutrients. 2013;5(3):829-851. Published 2013 Mar 12. doi:10.3390/nu5030829

Caricilli AM, Saad MJ. Gut microbiota composition and its effects on obesity and insulin resistance. Curr Opin Clin Nutr Metab Care. 2014 Jul;17(4):312-8. doi: 10.1097/MCO.0000000000000067.

Chelakkot C, Choi Y, Kim DK, Park HT, Ghim J, Kwon Y, Jeon J, Kim MS, Jee YK, Gho YS, Park HS, Kim YK, Ryu SH. Akkermansia muciniphila-derived extracellularvesicles influence gut permeability through the regulation of tight junctions. Exp Mol Med. 2018 Feb 23;50(2):e450. doi: 10.1038/emm.2017.282.

Dao MC, Everard A, Aron-Wisnewsky J, Sokolovska N, Prifti E, Verger EO, Kayser BD, Levenez F, Chilloux J, Hoyles L; MICRO-Obes Consortium, Dumas ME, Rizkalla SW, Doré J, Cani PD, Clément K. Akkermansia muciniphila and improved metabolic health during a dietary intervention in obesity: relationship with gut microbiome richness and ecology. Gut. 2016 Mar;65(3):426-36. doi:10.1136/gutjnl-2014-308778. 
Dalod M, Salazar-Mather TP, Malmgaard L, Lewis C, Asselin-Paturel C, Brière F, Trinchieri G, Biron CA. Interferon alpha/beta and interleukin 12 responses to viral infections: pathways regulating dendritic cell cytokine expression in vivo. J Exp Med. 2002 Feb 18;195(4):517-28. PubMed PMID: 11854364

D'Aiuto F, Gable D, Syed Z, Allen Y, Wanyonyi KL, White S, Gallagher JE. Evidence summary: The relationship between oral diseases and diabetes. Br Dent J. 2017 Jun 23;222(12):944-948. doi: 10.1038/sj.bdj.2017.544.

D'Aiuto F, Gkranias N, Bhowruth D, Khan T, Orlandi M, Suvan J, Masi S, Tsakos G, Hurel $S^{6}$, Hingorani AD, Donos N, Deanfield JE; TASTE Group. Systemic effects of periodontitis treatment in patients with type 2 diabetes: a 12 month, single-centre, investigator-masked, randomised trial. Lancet Diabetes Endocrinol. 2018 Dec;6(12):954-965. doi: 10.1016/S2213-8587(18)30038-X.

Dantas AM, Mohn CE, Burdet B, Zorrilla Zubilete M, Mandalunis PM, Elverdin JC, Fernández-Solari J. Ethanol consumption enhances periodontal inflammatory markers in rats. Arch Oral Biol. 2012 Sep;57(9):1211-7. doi:

10.1016/j.archoralbio.2012.02.008.

Di Giacinto C, Marinaro M, Sanchez M, Strober W, Boirivant M. Probiotics ameliorate recurrent Th1-mediated murine colitis by inducing IL-10 and IL-10-dependent TGFbeta-bearing regulatory cells. J Immunol. 2005 Mar 15;174(6):3237-46.

De Smedt T, Smith J, Baum P, Fanslow W, Butz E, Maliszewski C. Ox40 costimulation enhances the development of $T$ cell responses induced by dendritic cells in vivo. J Immunol. 2002 Jan 15;168(2):661-70.

Demmer RT, Squillaro A, Papapanou PN, Rosenbaum M, Friedewald WT, Jacobs DR Jr, Desvarieux M. Periodontal infection, systemic inflammation, and insulin resistance: results from the continuous National Health and Nutrition Examination Survey (NHANES) 1999-2004. Diabetes Care. 2012 Nov;35(11):2235-42. doi: 10.2337/dc12-0072.

Firouzi S, Majid HA, Ismail A, Kamaruddin NA, Barakatun-Nisak MY. Effect of multistrain probiotics (multi-strain microbial cell preparation) on glycemic control and other diabetes-related outcomes in people with type 2 diabetes: a randomized controlled trial. Eur J Nutr. 2017 Jun;56(4):1535-1550. doi: 10.1007/s00394-016-1199-8. 
Forbes JM, Cooper ME. Mechanisms of diabetic complications. Physiol Rev. 2013 Jan;93(1):137-88. doi: 10.1152/physrev.00045.2011. Review.

Forslund K, Hildebrand F, Nielsen T, Falony G, Le Chatelier E, Sunagawa S et AL.,Disentangling type 2 diabetes and metformin treatment signatures in the human gut microbiota. Nature. 2015 Dec 10;528(7581):262-266. doi: 10.1038/nature15766.

Furman BL, Candasamy M, Bhattamisra SK, Veettil SK. Reduction of blood glucose by plant extracts and their use in the treatment of diabetes mellitus; discrepancies in effectiveness between animal and human studies. J Ethnopharmacol. 2019 Jan 30;247:112264. doi: 10.1016/j.jep.2019.112264.

Gatej SM, Marino V, Bright R, Fitzsimmons TR, Gully N, Zilm P, Gibson RJ, Edwards S, Bartold PM. Probiotic Lactobacillus rhamnosus GG prevents alveolar bone loss in a mouse model of experimental periodontitis. J Clin Periodontol.2018 Feb;45(2):204212. doi: $10.1111 / \mathrm{jcpe} .12838$.

García-molina L, Lewis-mikhael AM, riquelme-Gallego B, Cano-ibáñez N, OliverasLópez MJ, Bueno-Cavanillas A. Improving type 2 diabetes mellitus glycaemic control through lifestyle modification implementing diet intervention: a systematic review and meta-analysis. Eur J Nutr. 2019 Nov 28. doi: 10.1007/s00394-019-02147-6.

Genco RJ, Borgnakke WS. Risk factors for periodontal disease. Periodontol 2000. 2013 Jun;62(1):59-94. doi: 10.1111/j.1600-0757.2012.00457.x.

Gillor O, Vriezen JA, Riley MA. The role of SOS boxes in enteric bacteriocin regulation. Microbiology. 2008 Jun;154(Pt 6):1783-92. doi:

10.1099/mic.0.2007/016139-0.

Graves DT, Fine D, Teng YT, Van Dyke TE, Hajishengallis G. The use of rodent models to investigate host-bacteria interactions related to periodontal diseases. $J$ Clin Periodontol. 2008 Feb;35(2):89-105. doi: 10.1111/j.1600-051X.2007.01172.x.

Geier MS, Butler RN, Howarth GS. Inflammatory bowel disease: current insights into pathogenesis and new therapeutic options; probiotics, prebiotics and synbiotics. Int $\mathrm{J}$ Food Microbiol. 2007 Apr 1;115(1):1-11. Epub 2006 Nov 28. Review.

Gupta G. Probiotics and periodontal health. J Med Life. 2011 Nov 14;4(4):387-94. Epub 2011 Nov 24. 
Goodson JM, Hartman ML, Shi P, Hasturk H, Yaskell T, Vargas J, Song X, Cugini M, Barake R, Alsmadi O, Al-Mutawa S, Ariga J, Soparkar P, Behbehani J, Behbehani K. The salivary microbiome is altered in the presence of a high salivary glucose concentration. PLoS One. 2017 Mar 1;12(3):e0170437. doi:10.1371/journal.pone.0170437. eCollection 2017.

Hugoson A, Laurell L. A prospective longitudinal study on periodontal boné height changes in a Swedish population. J Clin Periodontol. 2000 Sep;27(9):665-74.

Hajishengallis G, Lamont RJ. Beyond the red complex and into more complexity: the polymicrobial synergy and dysbiosis (PSD) model of periodontal disease etiology. Mol Oral Microbiol. 2012 Dec;27(6):409-19. doi: 10.1111/j.2041-1014.2012.00663.x.

Heczko PB, Strus M, Kochan P. Critical evaluation of probiotic activity of lactic acid bacteria and their effects. J Physiol Pharmacol. 2006 Nov;57 Suppl 9:5-12. Review.

Hajishengallis G. Periodontitis: from microbial immune subversion to systemic inflammation. Nat Rev Immunol. 2015 Jan;15(1):30-44. doi: 10.1038/nri3785

Harding JL, Pavkov ME, Magliano DJ, Shaw JE, Gregg EW. Global trends in diabetes complications: a review of current evidence. Diabetologia. 2019 Jan;62(1):316. doi: 10.1007/s00125-018-4711-2.

Herrera D, Retamal-Valdes B, Alonso B, Feres M. Acute periodontal lesion(periodontal abscesses and necrotizing periodontal diseases) and endoperiodontal lesions. J Periodontol. 2018 Jun;89 Suppl 1:S85-S102. doi: 10.1002/JPER.16-0642.

Ivanov II, McKenzie BS, Zhou L, Tadokoro CE, Lepelley A, Lafaille JJ, Cua DJ, Littman DR. The orphan nuclear receptor RORgammat directs the differentiation program of proinflammatory IL-17+ T helper cells. Cell. 2006 Sep 22;126(6):1121-33. PubMed PMID: 16990136.

Joshi, S., Kumar, S., Choudhury, A., Ponnusamy, M. P., \& Batra, S. K. (2014). Altered mucins(MUC) trafficking in benign and malignant conditions. Oncotarget, 5(17), 7272-7284. doi: 10.18632/oncotarget.2370

Krasse P, Carlsson B, Dahl C, Paulsson A, Nilsson A, Sinkiewicz G. Decreased gum bleeding and reduced gingivitis by the probiotic Lactobacillus reuteri. Swed Dent J. 2006;30(2):55-60. 
Kotsis V, Jordan J, Stabouli S, Antza C, Micic D, Jelaković B, Schlaich MP, Nilsson PM, Kreutz R, Mancia G, Tsioufis K, Grassi G. Cardiovascular, renal and liver protection with novel antidiabetic agents beyond blood glucose lowering in type 2 diabetes: consensus article from the European Society of Hypertension Working Group on Obesity, Diabetes and the High-risk Patient. J Hypertens. 2019 Nov 20. doi: 10.1097/HJH.0000000000002279.

Koromantzos PA, Makrilakis K, Dereka X, Katsilambros N, Vrotsos IA, Madianos PN. A randomized, controlled trial on the effect of non-surgical periodontal therapy in patients with type 2 diabetes. Part I: effect on periodontal status and glycaemic control. J Clin Periodontol. 2011 Feb;38(2):142-7. doi: 10.1111/j.1600 051X.2010.01652.x.

Kuboniwa M, Houser JR, Hendrickson EL, Wang Q, Alghamdi SA, Sakanaka A, Miller DP, Hutcherson JA, Wang T, Beck DAC, Whiteley M, Amano A, Wang H, Marcotte EM, Hackett M, Lamont RJ. Metabolic crosstalk regulates Porphyromonas gingivalis colonization and virulence during oral polymicrobial infection. Nat Microbiol. 2017 Nov;2(11):1493-1499. doi: 10.1038/s41564-017-0021-6.

Kobyliak N, Falalyeyeva T, Mykhalchyshyn G, Kyriienko D, Komissarenko I. Effect of alive probiotic on insulin resistance in type 2 diabetes patients: randomized clinical trial. Diabetes Metab. Syndr. 2018;12:617-624. doi: 10.1016/j.dsx.2018.04.015.

Kjellev S. The trefoil factor family - small peptides with multiple functionalities. Cell Mol Life Sci. 2009 Apr;66(8):1350-69. doi:10.1007/s00018-008-8646-5. Review.

Lally ET, Golub EE, Kieba IR. Identification and immunological characterization of the domain of Actinobacillus actinomycetemcomitans leukotoxin that determines its specificity for human target cells. J Biol Chem. 1994 Dec 9;269(49):31289-95.

Longo PL, Dabdoub S, Kumar P, Artese HPC, Dib SA, Romito GA, Mayer MPA. Glycaemic status affects the subgingival microbiome of diabetic patients. J Clin Periodontol. 2018 Aug;45(8):932-940. doi: 10.1111/jcpe.12908.

Lee CT, Huang HY, Sun TC, Karimbux N. Impact of Patient Compliance on Tooth Loss during Supportive Periodontal Therapy: A Systematic Review and Metaanalysis. J Dent Res. 2015 Jun;94(6):777-86. doi: 10.1177/0022034515578910. 
Lin $\mathrm{CH}$, Lin CC, Shibu MA, Liu CS, Kuo CH, Tsai FJ, Tsai $\mathrm{CH}$, Hsieh $\mathrm{CH}$, Chen $\mathrm{YH}$, Huang CY. Oral Lactobacillus reuteri GMN-32 treatment reduces blood glucose concentrations and promotes cardiac function in rats with streptozotocin-induced diabetes mellitus. Br J Nutr. 2014 Feb;111(4):598-605. doi:

10.1017/S0007114513002791.

Lim C, Chung BY, Pitman JL, McGill JJ, Pradhan S, Lee J, Keegan KP, Choe J, Allada R. Clockwork orange encodes a transcriptional repressor important for circadian-clock amplitude in Drosophila. Curr Biol. 2007 Jun 19;17(12):1082-9

Lim SM, Jeong JJ, Woo KH, Han MJ, Kim DH. Lactobacillus sakei OK67 ameliorates high-fat diet-induced blood glucose intolerance and obesity in mice by inhibiting gut microbiota lipopolysaccharide production and inducing colon tight junction protein expression. Nutr Res. 2016 Apr;36(4):337-348. doi: 10.1016/j.nutres.2015.12.001.

Lopez, R.; Hujoel, P.; Belibasakis, G. N. On putative periodontal pathogens: An epidemiological perspective. Virulence, v. 6, n. 3, p. 249-57, 2015.

Meldrum DR, Morris MA, Gambone JC. Obesity pandemic: causes, consequences, and solutions-but do we have the will? Fertil Steril. 2017 Apr;107(4):833-839. doi: 10.1016/j.fertnstert.2017.02.104.

Meredith LW, Wilson GK, Fletcher NF, McKeating JA. Hepatitis C virus entry: beyond receptors. Rev Med Virol. 2012 May;22(3):182-93. doi: 10.1002/rmv.723.

Marco ML, Pavan S, Kleerebezem M. Towards understanding molecular modes of probiotic action. Curr Opin Biotechnol. 2006 Apr;17(2):204-10.

Malm S, Jusko M, Eick S, Potempa J, Riesbeck K, Blom AM. Acquisition of complement inhibitor serine protease factor I and its cofactors C4b-binding protein and factor $\mathrm{H}$ by Prevotella intermedia. PLoS One. 2012;7(4):e34852. doi: 10.1371/journal.pone.0034852.

Matsubara VH, Bandara HM, Ishikawa KH, Mayer MP, Samaranayake LP. The role of probiotic bacteria in managing periodontal disease: a systematic review. Expert Rev Anti Infect Ther. 2016 Jul;14(7):643-55. doi: 10.1080/14787210.2016.1194198.

Matsuzaki T, Nagata Y, Kado S, Uchida K, Hashimoto S, Yokokura T. Effect of oral administration of Lactobacillus casei on alloxan-induced diabetes in mice. APMIS. 1997 Aug;105(8):637-42. 
Matsuzaki T, Yamazaki R, Hashimoto S, Yokokura T. Antidiabetic effects of na oral administration of Lactobacillus casei in a non-insulin-dependent diabetes mellitus (NIDDM) model using KK-Ay mice. Endocr J. 1997 Jun;44(3):357-65.

Mauri-Obradors E, Jané-Salas E, Sabater-Recolons Mdel M, Vinas M, López-López $\mathrm{J}$. Effect of nonsurgical periodontal treatment on glycosylated hemoglobin in diabetic patients: a systematic review. Odontology. 2015 Sep;103(3):301-13. doi: 10.1007/s10266-014-0165-2

Matsubara VH, Bandara HM, Ishikawa KH, Mayer MP, Samaranayake LP. The role of probiotic bacteria in managing periodontal disease: a systematic review. Expert Rev Anti Infect Ther. 2016 Jul;14(7):643-55. doi: 10.1080/14787210.2016.1194198.

Minty M, Canceil T, Serino M, Burcelin R, Tercé F, Blasco-Baque V. Oral microbiotainduced periodontitis: a new risk factor of metabolic diseases. Ver Endocr Metab Disord. 2019 Nov 18. doi: 10.1007/s11154-019-09526-8.

McGonigle P, Ruggeri B. Animal models of human disease: challenges in enabling translation. Biochem Pharmacol. 2014 Jan 1;87(1):162-71.

doi:10.1016/j.bcp.2013.08.006.

Mobini R, Tremaroli V, Ståhlman M, Karlsson F, Levin M, Ljungberg M, Sohlin M, Bertéus Forslund H, Perkins R, Bäckhed F, Jansson PA. Metabolic effects of Lactobacillus reuteri DSM 17938 in people with type 2 diabetes: A randomized controlled trial. Diabetes Obes Metab. 2017 Apr;19(4):579-589. doi: 10.1111/dom.12861.

Nepomuceno R, Villela BS, Corbi SC, Bastos AS, Dos Santos RA, Takahashi CS, Orrico SR, Scarel-Caminaga RM. Dyslipidemia rather than Type 2 Diabetes Mellitus or Chronic Periodontitis Affects the Systemic Expression of Pro- and AntiInflammatory Genes. Mediators Inflamm. 2017;2017:1491405. doi: $10.1155 / 2017 / 1491405$.

Nibali L. Aggressive Periodontitis: microbes and host response, who to blame? Virulence. 2015;6(3):223-8. doi: 10.4161/21505594.2014.986407.

Naito Y, Uchiyama K, Takagi T. A next-generation beneficial microbe: Akkermansia muciniphila. J Clin Biochem Nutr. 2018 Jul;63(1):33-35. doi: 10.3164/jcbn.18-57. 
Nakajima M, Arimatsu K, Kato T, Matsuda Y, Minagawa T, Takahashi N, Ohno H, Yamazaki K. Oral Administration of P. gingivalis Induces Dysbiosis of Gut Microbiota and Impaired Barrier Function Leading to Dissemination of Enterobacteria to the Liver. PLoS One. 2015 Jul 28;10(7):e0134234. doi: 10.1371/journal.pone.0134234. eCollection 2015.

Niv, Y. (2016). Mucin gene expression in the intestine of ulcerative colitis patients: a systematic review and meta-analysis. European Journal of Gastroenterology \& Hepatology,2016, 1241-1245

Oliveira LF, Salvador SL, Silva PH, Furlaneto FA, Figueiredo L, Casarin R, et al. Benefits of Bifidobacterium animalis subsp. lactis Probiotic in Experimental Periodontitis. J Periodontol. 2017 Feb;88(2):197-208. doi: 10.1902/jop.2016.160217.

Ostadrahimi A, Taghizadeh A, Mobasseri M, Farrin N, Payahoo L, Beyramalipoor Gheshlaghi Z, et al. Effect of probiotic fermented milk (kefir) on glycemic control and lipid profile in type 2 diabetic patients: a randomized double-blind placebo-controlled clinical trial. Iran J Public Health. 2015 Feb;44(2):228-37.

Papapanou PN, Sanz M, Buduneli N, Dietrich T, Feres M, Fine DH, et al. Periodontitis: Consensus report of workgroup 2 of the 2017 World Workshop on the Classification of Periodontal and Peri-Implant Diseases and Conditions. J Periodontol. 2018 Jun;89 Suppl 1:S173-S182. doi: 10.1002/JPER.17-0721.

Pascale A, Marchesi N, Govoni S, Coppola A, Gazzaruso C. The role of gut microbiota in obesity, diabetes mellitus, and effect of metformin: new insights into old diseases. Curr Opin Pharmacol. 2019 Dec;49:1-5. doi: 10.1016/j.coph.2019.03.011.

Pickup JC, Crook MA. Is type II diabetes mellitus a disease of the innate immune system? Diabetologia. 1998 Oct;41(10):1241-8. Review.

Palm NW, de Zoete MR, Flavell RA. Immune-microbiota interactions in health and disease. Clin Immunol. 2015 Aug;159(2):122-127. doi: 10.1016/j.clim.2015.05.014.

Panwar H, Rashmi HM, Batish VK, Grover S. Probiotics as potential biotherapeutics in the management of type 2 diabetes - prospects and perspectives. Diabetes Metab Res Rev. 2013 Feb;29(2):103-12. doi: 10.1002/dmrr.2376. 
Pasini $\mathrm{E}^{1}$, Corsetti $\mathrm{G}^{2}$, Assanelli $\mathrm{D}^{3}$, Testa $\mathrm{C}^{4}$, Romano $\mathrm{C}^{5}$, Dioguardi FS ${ }^{6}$, et al. Effects of chronic exercise on gut microbiota and intestinal barrier in human with type 2 diabetes. Minerva Med. 2019 Feb;110(1):3-11. doi: 10.23736/S00264806.18.05589-1

Polak D, Ferdman O, Houri-Haddad Y. Porphyromonas gingivalis Capsule-Mediated Coaggregation as a Virulence Factor in Mixed Infection With Fusobacterium nucleatum. J Periodontol. 2017 May;88(5):502-510. doi: 10.1902/jop.2016.160397.

Polak D, Shapira L. An update on the evidence for pathogenic mechanisms that may link periodontitis and diabetes. J Clin Periodontol. 2018 Feb;45(2):150-166. doi: $10.1111 /$ jcpe. 12803.

Parekh M, Romano V, Ruzza A, Kaye SB, Ponzin D, Ahmad S, Ferrari S. Culturing Discarded Peripheral Human Corneal Endothelial Cells From the Tissues Deemed for Preloaded DMEK Transplants. Cornea. 2019 Sep;38(9):1175-1181. doi: 10.1097/ICO.0000000000001998.

Potempa M, Potempa J, Kantyka T, Nguyen KA, Wawrzonek K, Manandhar SP, Popadiak K, Riesbeck K, Eick S, Blom AM. Interpain A, a cysteine proteinase from Prevotella intermedia, inhibits complement by degrading complement factor C3. PLoS Pathog. 2009 Feb;5(2):e1000316. doi: 10.1371/journal.ppat.1000316.

Promsudthi A, Poomsawat S, Limsricharoen W. The role of Toll-like receptor 2 and 4 ingingival tissues of chronic periodontitis subjects with type 2 diabetes. J Periodontol Res. 2014;9(3):346-54.

Pumerantz AS, Bissett SM, Dong F, Ochoa C, Wassall RR, Davila H, Barbee M, Nguyen J, Vila P, Preshaw PM. Standardized screening for periodontitis as na integral part of multidisciplinary management of adults with type 2 diabetes: an observational cross-sectional study of cohorts in the USA and UK. BMJ Open Diabetes Res Care. 2017 Jul 7;5(1):e000413. doi: 10.1136/bmjdrc-2017-000413.

Raff A, Hunt LC. Probiotics for periodontal health: a review of the literature. Journalof dental hygiene. 2012;86:71-81.

Rickard AH, Gilbert P, High NJ, Kolenbrander PE, Handley PS. Bacterial coaggregation: an integral process in the development of multi-species biofilms. Trends Microbiol. 2003 Feb;11(2):94-100. Review. 
Reagan-Shaw S, Nihal M, Ahmad N. Dose translation from animal to human studies revisited. FASEB J. 2008 Mar;22(3):659-61. Epub 2007 Oct 17 Salgaço MK, Oliveira LGS, Costa GN, Bianchi F, Sivieri K. Relationship between gut microbiota, probiotics, and type 2 diabetes mellitus. Appl Microbiol Biotechnol. 2019 Dec;103(23-24):92299238. doi: 10.1007/s00253-019-10156-y.

Rezazadeh A, Shahabi S, Bagheri M, Nabizadeh E, Jazani NH. The protective effect of Lactobacillus and Bifidobacterium as the gut microbiota members against chronic urticaria. Int Immunopharmacol. 2018 Jun;59:168-173. doi:

10.1016/j.intimp.2018.04.007.

Riccia DN, Bizzini F, Perilli MG, Polimeni A, Trinchieri V, Amicosante G, Cifone MG. Anti-inflammatory effects of Lactobacillus brevis (CD2) on periodontal disease. Oral Dis. 2007 Jul;13(4):376-85.

Shi B, Lux R, Klokkevold P, Chang M, Barnard E, Haake S, Li H. The subgingival microbiome associated with periodontitis in type 2 diabetes mellitus. ISME J. 2019 Oct 31. doi: 10.1038/s41396-019-0544-3.

Socransky SS, Haffajee AD, Cugini MA, Smith C, Kent RL Jr. Microbial complexes in subgingival plaque. J Clin Periodontol. 1998 Feb;25(2):134-44.

Staab B, Eick S, Knöfler G, Jentsch H. The influence of a probiotic milk drink on the development of gingivitis: a pilot study. J Clin Periodontol. 2009 Oct;36(10):850-6. doi: 10.1111/j.1600-051X.2009.01459.x.

Stafeev AV, Vorotnikov EI. Ratner MY Menshikov YEV. Parfyonova Latent Inflammation and Insulin Resistance in Adipose Tissue. Int J Endocrinol. 2017; 2017: 5076732. doi: $10.1155 / 2017 / 5076732$

Socransky SS, Haffajee AD. Dental biofilms: difficult therapeutic targets. Periodontology 2000. 2002;28(1):12-55.

Soskolne WA, Klinger A. The relationship between periodontal diseases and diabetes: an overview. Ann Periodontol. 2001 Dec;6(1):91-8. Review

Suvan J, D'Aiuto F, Moles DR, Petrie A, Donos N. Association between overweight/obesity and periodontitis in adults. A systematic review. Obes Rev. 2011 May;12(5):e381-404. doi: 10.1111/j.1467-789X.2010.00808.x. 
Shimauchi H, Mayanagi G, Nakaya S, Minamibuchi M, Ito Y, Yamaki K, Hirata H. Improvement of periodontal condition by probiotics with Lactobacillus salivarius WB21: a randomized, double-blind, placebo-controlled study. J Clin Periodontol. 2008 Oct;35(10):897-905. doi: 10.1111/j.1600-051X.2008.01306.x.

Steed E, Balda MS, Matter K. Dynamics and functions of tight junctions. Trends Cell Biol. 2010 Mar;20(3):142-9. doi: 10.1016/j.tcb.2009.12.002.

Shiou SR, Yu Y, Guo Y, He SM, Mziray-Andrew CH, Hoenig J, Sun J, Petrof EO, Claud EC. Synergistic protection of combined probiotic conditioned media against neonatal necrotizing enterocolitis-like intestinal injury. PLoS One. 2013 May 24;8(5):e65108. doi: 10.1371/journal.pone.0065108.

Sun Y, Li Y, Luo D, Liao DJ. Pseudogenes as weaknesses of ACTB (Actb) and GAPDH (Gapdh) used as reference genes in reverse transcription and polymerase chain reactions. PLoS One. 2012;7(8):e41659. doi: 10.1371/journal.pone.0041659.

Tamboli CP, Neut C, Desreumaux P, Colombel JF. Dysbiosis in inflammatory bowel disease. Gut. 2004 Jan;53(1):1-4. PubMed PMID: 14684564;

Tai FW, Syn WK, Alazawi W. Practical approach to non-alcoholic fatty liver disease in patients with diabetes. Diabet Med. 2015 Sep;32(9):1121-33. doi:

$10.1111 / \mathrm{dme} .12725$.

Toiviainen A, Jalasvuori H, Lahti E, Gursoy U, Salminen S, Fontana M, Flannagan S, Eckert G, Kokaras A, Paster B, Söderling E. Impact of orally administered lozenges with Lactobacillus rhamnosus GG and Bifidobacterium animalis subsp. lactis BB-12 on the number of salivary mutans streptococci, amount of plaque, gingival inflammation and the oral microbiome in healthy adults. Clin Oral Investig. 2015 Jan;19(1):77-83. doi: 10.1007/s00784-014-1221-6.

Tonetti MS, Van Dyke TE; working group 1 of the joint EFP/AAP workshop. Periodontitis and atherosclerotic cardiovascular disease: consensus report of the Joint EFP/AAP Workshop on Periodontitis and Systemic Diseases. J Periodontol. 2013 Apr;84(4 Suppl):S24-9. doi: 10.1902/jop.2013.1340019.v

Twetman S, Derawi B, Keller M, Ekstrand K, Yucel-Lindberg T, Stecksen-Blicks C. Short-term effect of chewing gums containing probiotic Lactobacillus reuteri on the levels of inflammatory mediators in gingival crevicular fluid. Acta Odontol Scand. 2009;67(1):19-24. doi: 10.1080/00016350802516170. 
Teughels W, Durukan A, Ozcelik O, Pauwels M, Quirynen M, Haytac MC. Clinical and microbiological effects of Lactobacillus reuteri probiotics in the treatment of chronic periodontitis: a randomized placebo-controlled study. J Clin Periodontol. 2013 Nov;40(11):1025-35. doi: 10.1111/jcpe.12155

Vogt L, Meyer D, Pullens G, Faas M, Smelt M, Venema K, Ramasamy U, Schols HA, De Vos P. Immunological properties of inulin-type fructans. Crit Rev Food Sci Nutr. 2015;55(3):414-36. doi: 10.1080/10408398.2012.656772.

Vivekananda MR, Vandana KL, Bhat KG. Effect of the probiotic Lactobacilli vreuteri (Prodentis) in the management of periodontal disease: a preliminary randomized clinical trial. J Oral Microbiol. 2010 Nov 2;2. doi: 10.3402/jom.v2i0.5344.

Wang M, Krauss JL, Domon H, Hosur KB, Liang S, Magotti P, Triantafilou M, Triantafilou K, Lambris JD, Hajishengallis G. Microbial hijacking of complement-tolllike receptor crosstalk. Sci Signal. 2010 Feb 16;3(109):ra11. doi:

10.1126/scisignal.2000697.

Yoshimura M, Ohara N, Kondo Y, Shoji M, Okano S, Nakano Y, Abiko Y, Nakayama $\mathrm{K}$. Proteome analysis of Porphyromonas gingivalis cells placed in a subcutaneous chamber of mice. Oral Microbiol Immunol. 2008 Oct;23(5):413-8. doi: 10.1111/j.1399302X.2008.00444.x.

Yang X, Zhang J, Ni J, Ouyang B, Wang D, Luo S, Xie B, Xuan D. Toll-like receptor 4-mediated hyper-responsiveness of gingival epithelial cells to lipopolysaccharide in high-glucose environments. J Periodontol. 2014 Nov;85(11):1620-8. doi:

10.1902/jop.2014.140087.

Zhang J, Kobert K, Flouri T, Stamatakis A. PEAR: a fast and accurate Illumina Paired-End reAd mergeR. Bioinformatics. 2014 Mar 1;30(5):614-20. doi:

10.1093/bioinformatics/btt593.

Zhao L, Wang Y, Zhang G, Zhang T, Lou J, Liu J. L-Arabinose Elicits Gut-Derived Hydrogen Production and Ameliorates Metabolic Syndrome in C57BL/6J Mice on High-Fat-Diet. Nutrients. 2019 Dec 13;11(12). pii: E3054. doi: 10.3390/nu11123054. PubMed PMID: 31847305.

Yadav, H.; Jain, S.; Sinha, P. R. ORral administration of dahi containing probiotic Lactobacillus acidophilus and Lactobacillus casei delayed the progression of streptozotocin-induced diabetes in rats. J Dairy Res. 2008;75(2):189-95. 
Yamawaki I, Taguchi Y, Komasa S, Tanaka A, Umeda M. Effects of glucose concentration on osteogenic differentiation of type II diabetes mellitus rat boné marrow-derived mesenchymal stromal cells on a nano-scale modified titanium. J Periodontal Res. 2017 Aug;52(4):761-771. doi: 10.1111/jre.12446.

Yang S, Ajilore O, Wu M, Lamar M, Kumar A. Impaired macromolecular protein pools in fronto-striato-thalamic circuits in type 2 diabetes revealed by magnetization transfer imaging. Diabetes. 2015 Jan;64(1):183-92. doi: 10.2337/db14-0316. Epub 2014 Aug 4. 



ANEXO A - Aprovação do CEUA - ICB

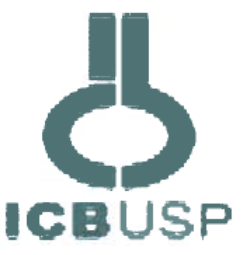

Cidade Universitária "Armando de Salles Oliveira", Butantă, Săo Paulo, SP - Av. Professor Lineu Prestes, 2415 - ICB III - 05508000 Comissắo de Ética no Uso de Animais - Telefone (11) 3091-7733 - e-mail: cep@icb.usp.br

Decl. CEUA.109.2019

\section{E C L A R A Ç Ã O}

Em adendo ao Certificado 111/2017/CEUA, válido até 09/10/2021, e por solicitação do(a) Prof.(a) Dr.(a) Marcia Pinto Alves Mayer, do Departamento de Microbiologia, responsável pela linha de Pesquisa, autorizo a inclusão do(a) aluno(a) Biannka Pompeo Cardoso na equipe do Projeto de Pesquisa: "Efeito dos probióticos sobre a modulação da resposta imune e nível de perda óssea alveolar promovida por periodontite induzida em camundongos saudáveis e diabéticos", uma vez que se trata de utilização da mesma espécie animal e de métodos experimentais similares ao Projeto.

São Paulo, 18 de junho de 2019.

\section{Luciare valinia sita}

Profa. Dra. Luciane Valéria Sita

Coordenadora da CEUA-ICB/USP 



ANEXO B - Parecer do Comitê de Ética - FOUSP

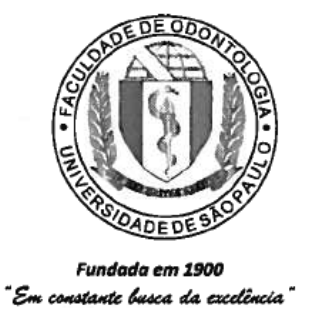

\section{Universidade de São PaUlo FACULDADE DE ODONTOLOGIA}

Comissão de Ética no Uso de Animais

Tel. (11) 30917842

ceuafo@usp.br

\section{CERTIFICADO}

Certificamos que a proposta intitulada: "Efeito doprobiótico L. acidophilus LA5 em modelo de periodontite induzida em camundongos diabéticos" registrada com o $n^{\circ}$ 026/2019, sob a responsabilidade da Profa. Dra. Marcia Pinto Alves Mayer, Biannka Pomepo Cardoso, Natali Shimabukuro, Amália Cristina de Souza Cataruci, Karin Kitomi Ishikawa, Manuela Rocha Bueno, Marina Parluppi, que envolve a produção, manutenção ou utilização de animais pertencentes ao filo Chordata, subfilo Vertebrata, para fins de pesquisa cientifica encontra-se de acordo com os preceitos da Lei $n^{\circ} 11.794$, de 8 de outubro de 2008 , do Decreto $n^{\circ} 6.899$, de 15 de julho de 2009, e com as normas editadas pelo Conselho Nacional de Controle de Experimentação Animal (CONCEA), e foi aprovado pela COMISSÃO DE ÉTICA NO USO DE ANIMAIS (CEUA) da Faculdade de Odontologia da USP, em reunião de 08/10/2019.

\begin{tabular}{|l|l|}
\hline Finalidade & $($ ) Ensino ( X ) Pesquisa Científica \\
\hline Vigência da autorização & $01 / 12 / 2019$ a 01/12/2020 \\
\hline Espécie/linhagem/raça & Rato heterogênico Wistar \\
\hline$N^{0}$ de animais & 40 \\
\hline Peso/ldade & 4 semanas \\
\hline Sexo & M \\
\hline Origem & Biotério da Faculdade de Medicina da USP \\
\hline
\end{tabular}

São Paulo, 08 de outubro de 2019.

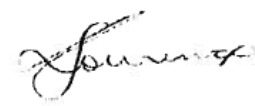

Profa. Associada Dra. Silvia Vanessa Lourenço Coordenadora do CEUA-FOUSP 